\title{
Has the Information Channel of Monetary Policy Disappeared? Revisiting the Empirical Evidence
}

\author{
Lukas Hoesch \\ Univ. Pompeu Fabra \\ Barcelona School of Economics \\ Barbara Rossi \\ ICREA - Univ. Pompeu Fabra \\ Barcelona School of Economics and CREI \\ Tatevik Sekhposyan, \\ Federal Reserve Bank of San Francisco \\ Texas A\&M University \\ February 2020 \\ Working Paper 2020-08 \\ https://www.frbsf.org/economic-research/publications/working-papers/2020/08/
}

\section{Suggested citation:}

Hoesch, Lukas, Barbara Rossi, Tatevik Sekhposyan. 2020. "Has the Information Channel of Monetary Policy Disappeared? Revisiting the Empirical Evidence,” Federal Reserve Bank of San Francisco Working Paper 2020-08. https://doi.org/10.24148/wp2020-08

The views in this paper are solely the responsibility of the authors and should not be interpreted as reflecting the views of the Federal Reserve Bank of San Francisco or the Board of Governors of the Federal Reserve System. 


\title{
Has the Information Channel of Monetary Policy Disappeared? Revisiting the Empirical Evidence
}

\author{
Lukas Hoesch \\ Barbara Rossi* \\ Tatevik Sekhposyan \\ Univ. Pompeu Fabra, \\ ICREA - Univ. Pompeu Fabra, \\ Federal Reserve Bank \\ and Barcelona School of \\ Barcelona School of \\ of San Francisco, \\ Economics \\ Economics, and CREI \\ Texas A\&M University
}

This draft: February 27, 2020

\begin{abstract}
Does the Federal Reserve have an "information advantage" in forecasting macroeconomic variables beyond what is known to private sector forecasters? And are market participants reacting only to monetary policy shocks or also to future information on the state of the economy that the Federal Reserve communicates in its announcements via an "information channel"? This paper investigates the evolution of the information channel over time. Although the information channel appears to be important historically, we find no empirical evidence of its presence in the recent years once instabilities are accounted for.
\end{abstract}

JEL classification: C11, C14, C22, C52, C53

Keywords: Forecasting, Monetary Policy, Instabilities, Time Variation, Survey Forecasts, Information Channel of Monetary Policy.

${ }^{*}$ Corresponding author: Barbara Rossi, CREI, Universitat Pompeu Fabra, C. Ramon Trias Fargas 25-27, Mercé Rodoreda Bldg., 08005 Barcelona, Spain. Email: barbara.rossi@upf.edu

Acknowledgements: We thank D. Giannone and conference participants at the Federal Reserve Bank of New York. Supported by the ERC Grant 615608 and the Cerca Programme/Generalitat de Catalunya. The Barcelona GSE acknowledges financial support from the Spanish ministry of the Economy and Competitiveness through the Severo Ochoa Programme for Centers of Excellence in R\&D (SEV-20150063). The views in this paper are solely the responsibility of the authors and should not be interpreted as reflecting the views of the Federal Reserve Bank of San Francisco or the Board of Governors of the Federal Reserve System. 


\section{Introduction}

The recent literature has found that, in response to unexpected increases in interest rates, survey-based estimates of expected output growth rise while those of inflation decline (Campbell et al., 2012, 2017). This is contrary to the common New Keynesian wisdom that contractionary monetary policy causes a decline in output growth and inflation and, consequently, their expectations. An explanation for this puzzling fact is the existence of the so-called "information channel". According to the information channel, agents update their beliefs after an unexpected monetary policy announcement not only because they learn about the current and future path of monetary policy, but also because they learn new information about economic fundamentals. The intuition is that the Federal Reserve communicates not only the future path of monetary policy but also how optimistic it is about the current and future state of the economy: if the Federal Reserve's expectation of future fundamentals is different from the state of the economy perceived by market participants, market participants will update their expectations. In the latter case, the responses to a monetary policy shock may not be estimated correctly. In fact, if the monetary policy tightening is the endogenous reaction to a future state of the economy that is more positive than markets anticipated, the latter can update their expectations and anticipate that output and inflation might indeed rise.

A crucial assumption behind the information channel is that the central bank has additional knowledge about the state of the economy relative to market participants; that is, it has an "information advantage". When this is the case, market participants will update their information about the state of the economy based on the new information contained in central banks' announcements.

How important is the "signaling channel" empirically? Does the Federal Reserve indeed have an "information advantage" in forecasting macroeconomic variables beyond what is known to private forecasters? And does this matter when estimating the response of the economy to monetary policy shocks?

We revisit the empirical evidence by making an important point of departure from the previous literature; namely, we allow for instabilities. That is, we allow the "information advantage" of the Federal Reserve relative to market participants to change over time. As we show, this is an important empirical feature of the data. In fact, both the Federal Reserve and market participants periodically and systematically over- and under-predict macroeconomic variables, depending on the period of time - the most likely reason being the existence of unforecastable and persistent shocks in the economy. Furthermore, we also allow the transmission mechanism of monetary policy shocks to vary over time, depending on whether the information advantage is present in the data. We show that the latter matters when estimating the effects of a monetary policy shock in the economy: at times when the central bank has an "informational advantage", the information channel 
is at work: the responses are confounded, and the researcher may estimate an expansionary response to a contractionary monetary policy shock. On the other hand, when the information advantage disappears, the information channel loses importance: the perils of confoundedness disappear, and researchers are able to correctly recover the response in the data.

Once we take instabilities into account, we find no evidence that the information channel is empirically relevant in the most recent period. Since the Federal Reserve has no shorthorizon information advantage regarding the state of the economy relative to market participants, we also verify that the private forecasters' reaction to monetary policy shocks is less sensitive in the latter period as well. The decline in the relevance in the signaling channel could be related to the improved communication strategies of the Federal Reserve over time.

Our paper is related to various strands of the literature. First, our paper is related to the large literature estimating the effects of monetary policy shocks - see Christiano et al. (1999, 2005), among others. Traditional VAR regressions conventionally estimate a positive, hump-shaped response of output and inflation to an expansionary monetary policy shock measured by an exogenous movement in the Federal Funds rate. However, as Campbell et al. (2012) and Nakamura and Steinsson (2018) show, survey expectations of output growth typically rise after an unexpected monetary policy tightening, thus contradicting the predictions of standard economic models. Nakamura and Steinsson (2018) explain the latter finding in a theoretical model with a signaling channel, where monetary policy shocks affects not only the real interest rate, but also the private sector's belief about the path of the natural rate of interest; this happens because, as the central bank tracks the natural rate of interest, its announcements indeed reveal news about it. The presence of informational effects and their evolution over time is the objective of our paper. MirandaAgrippino and Ricco (2018) investigate the responses of core macroeconomic aggregates to monetary policy announcements using an identification strategy robust to information frictions. Their instrument is the component of high-frequency market surprises at the time of a monetary policy announcement that is orthogonal to both the central bank's own forecasts as well as previous market surprises. In a similar spirit, Jarocinski and Karadi (2018) use sign restrictions to separately identify monetary policy and "information" shocks from the stock price dynamics. Andrade and Ferroni (2018) investigate the information channel in forward guidance announcements in the Euro area. ${ }^{1}$

Secondly, there is a large literature on the evaluation of central banks' forecasts, and the quality of the Federal Reserve's own internal forecasts relative to the private sector's has been extensively studied in the literature. In a seminal contribution, Romer and Romer

\footnotetext{
${ }^{1}$ On the other hand, Bundick and Smith (2019) and Inoue and Rossi (2019) show, using completely different methodologies, that the response of the economy to forward guidance shock is indeed consistent with standard predictions from New Keynesian models.
} 
(2000) showed that the Federal Reserve has an information advantage relative to the private sector when forecasting inflation. On the other hand, both D'Agostino and Whelan (2008) and Rossi and Sekhposyan (2016) find evidence of instabilities in the information advantage. D'Agostino and Whelan (2008) show that the Federal Reserve's superior forecasting performance relative to survey forecasts deteriorated between 1990 and 2001 across all forecast horizons, and only survived at short horizons. Our contribution is instead to document that even the central bank's short-horizon forecast advantage disappeared in the most recent period. In addition, while the analysis in D'Agostino and Whelan (2008) is based on ad-hoc sub-samples, we consider general patterns of time-variation and let the data uncover the periods in time when the forecast advantage appears/disappears. Rossi and Sekhposyan (2016) also show that the evidence of central banks' forecast advantage in predicting inflation depends on the time period, and has deteriorated over time. Our paper considers instead a wider range of macroeconomic variables, such as real output growth, unemployment and, especially, interest rates, linking the forecast advantage to the information channel of monetary policy.

Lastly, our work is more distantly related to the literature on forecast rationality, in particular Faust and Wright (2009), Patton and Timmermann (2012), Croushore (2012) and Rossi and Sekhposyan (2016). Faust and Wright (2009), Patton and Timmermann (2012) and Croushore (2012) note that whether inflation forecasts are rational depends on the sub-sample period used for the forecast evaluation, while Rossi and Sekhposyan (2016) formally investigate the rationality of the Federal Reserve Greenbook/Tealbook forecasts as well as private sector forecasts of inflation in the presence of instabilities. Several studies have also analyzed the relative forecasting performance of central banks' and surveys' forecasts: D'Agostino and Whelan (2008) and D'Agostino et al. (2006) note that both the central bank and the survey forecasts worsened relative to naive benchmark models between 1990 and 2001.

The paper is structured as follows. Section 2 discusses the motivation that inspired the analysis in this paper, and Section 3 provides details on the data. Sections 4 discusses the empirical results on the information channel, and Section 5 summarizes our findings on the information advantage. Section 6 investigates how private forecasters react to information shocks and Section 7 concludes.

\section{Are Instabilities Important? And Why?}

According to the "information channel" theory, central bank communications can have a policy effect because they reveal private information to market participants. An important assumption behind this theory is that the central bank has (useful) private information about the state of the economy that could potentially be conveyed to market participants 
via its announcements. ${ }^{2}$ When investigating the presence of an information channel, one should verify this necessary assumption empirically by addressing the following two questions. First, are the forecasts made by central banks useful for market participants i.e. are their forecasts unbiased and efficient? And, second, is there empirical evidence that forecasts of macroeconomic fundamentals made by central banks add any useful information to those made by private forecasters?

An important issue that one encounters in practice when attempting to answer these questions is that the forecasts are unstable. The presence of instabilities is illustrated in Figure 1. The left column of Figure 1 reports one-quarter-ahead forecasts of U.S. inflation, GDP growth, the unemployment rate and the interest rate made by the central bank and private market participants, together with the realized values. The figures in the right column plot the forecast errors associated with the forecasts of those variables. The dashed green line reports the forecasts/forecast errors by the Federal Reserve Board staff in their Greenbook/Tealbook projections, the blue solid line reports the consensus forecasts/forecast errors of the Blue Chip Economic Indicators (BCEI). The dotted gray line indicates the associated realized values (left panel) and the horizontal line at zero indicates no forecast error (right panel). The data and their sources are discussed in detail in the next section.

First, by visually inspecting the forecasts and forecast errors, it is evident that there are periods of time when the forecasts systematically under- or over-predict the target. Hence, there are periods in time when the forecasts are biased and misspecified.

Second, even when biased, a forecast might have an advantage relative to another forecast. Consider the question of a potential information advantage of Greenbook/Tealbook forecasts over the forecasts from the Blue-Chip Economic Indicators survey. Looking at the forecast errors depicted in the right column of Figure 1, it is evident that there is considerable time-variation in the relative performance of the forecasts. While there are periods when both forecasts seem to perform equally well or equally badly, there are also periods when the Greenbook/Tealbook forecasts have consistently larger forecast errors than the BCEI, and vice versa.

When there is time variation in the relative forecasting performance or when the forecast bias is time-varying, analyses based on a full sample are invalid. For instance, if the full sample comprises periods of over-prediction as well as under-prediction, on average, the forecasts might look as if they were unbiased - see Rossi and Sekhposyan (2016). Similarly, when the relative performance of central bank's and private institution's forecasts systematically varies over time, we might conclude that the central bank does not have an information advantage when in reality there is an information advantage for certain periods - see Giacomini and Rossi (2010). In this paper, we thus investigate the proper-

\footnotetext{
${ }^{2}$ If the central bank did not have such useful private information, it would not be clear why the private sector should be updating its expectations based on erroneous information.
} 
Figure 1: Forecasts and Forecast Errors at $h=1$

A

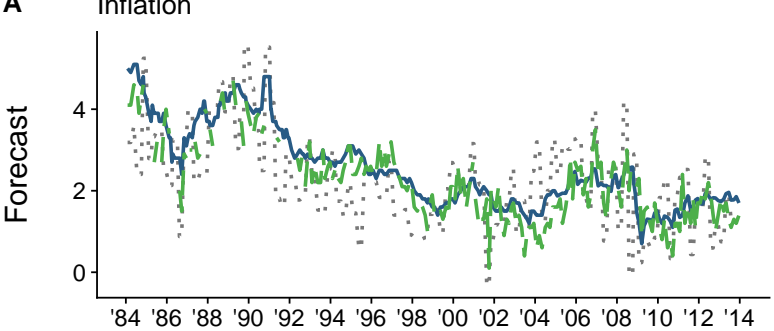

B GDP Growth

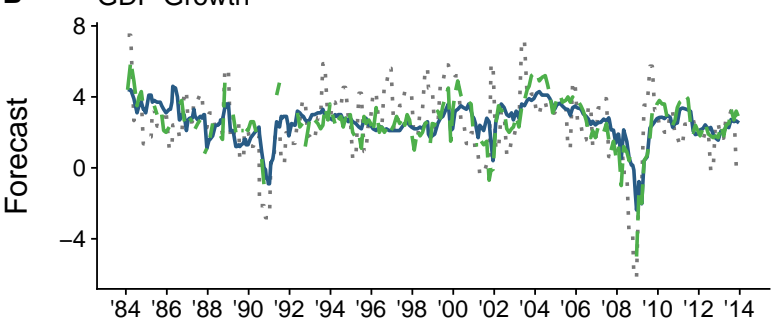

C Unemployment Rate

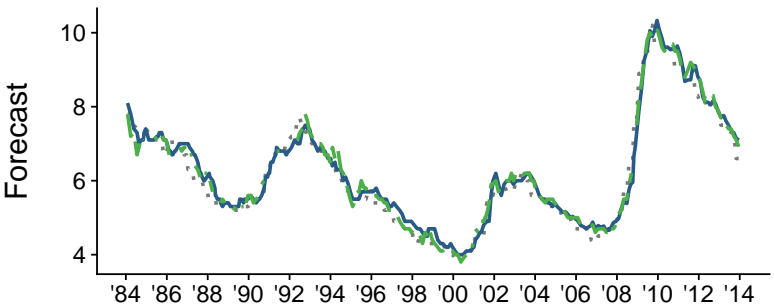

D

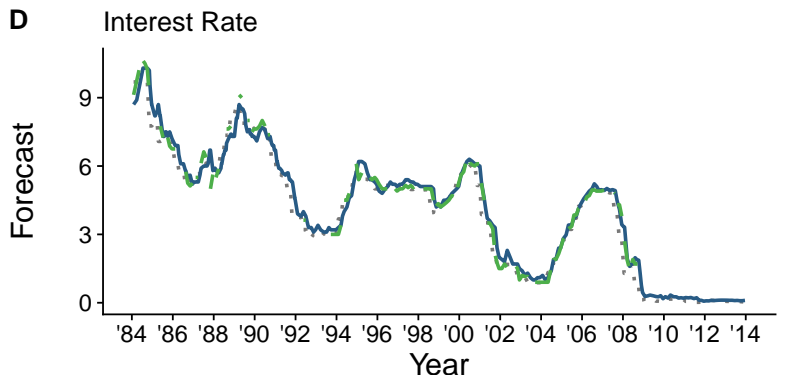

Inflation

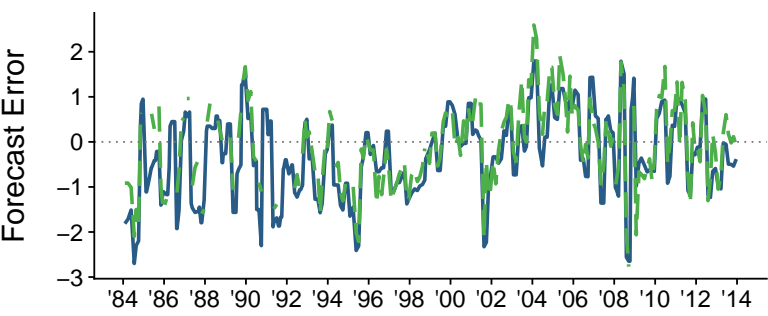

GDP Growth
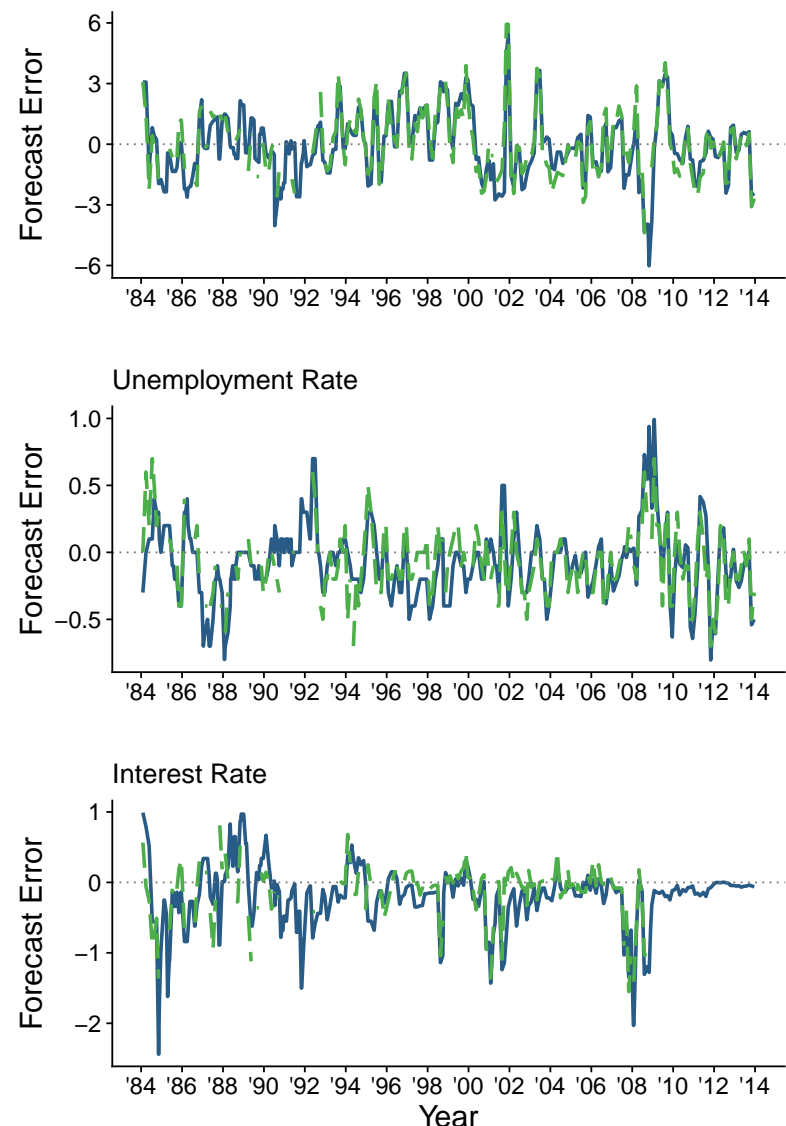

Notes. The figure reports one-quarter-ahead forecasts of U.S. inflation, GDP growth, the unemployment rate and the interest rate made by central banks and private market participants together with the realized values in the left column. The right column reports the forecast errors associated with the forecasts of the same variables, computed as the difference between the realized values and the respective forecast. The dashed green line reports the forecasts/forecast errors made by the Federal Reserve Board staff in their Greenbook/Tealbook projections, the blue solid line reports the consensus forecasts/forecast errors reported in the Blue Chip Economic Indicators. The dotted gray line indicates the associated realized values (left panel) and a line indicating no forecast error (right panel). If a forecast at a particular time is not available, it is reported as a gap in the series. 
ties of the forecasts by employing a Fluctuation Rationality test, that assesses forecasting optimality in a way that is robust to instabilities.

To evaluate whether forecasts are rational, consider the following regression:

$$
x_{t+h}-x_{t+h \mid t}^{i}=\alpha+\beta x_{t+h \mid t}^{i}+\varepsilon_{t+h},
$$

where $x_{t+h}$ denotes a real-time realization of either real GDP growth, the GDP deflator inflation, the unemployment rate, or the interest rate; $x_{t+h \mid t}^{i}$ is the forecast of $x_{t+h}$ based on information available at time $t$ by either the Blue Chip Economic Indicators' consensus forecast ( $\mathrm{i}=\mathrm{BCEI}$ ) or the Greenbook/Tealbook forecasts $(\mathrm{i}=\mathrm{GB}) ; h$ is the forecast horizon in quarters; and $\varepsilon_{t+h}$ is the forecast error. ${ }^{3}$

Figures 2 to 5 depict the Fluctuation Rationality test statistic over time together with the $5 \%$ critical values for forecast horizons $h=0,1,2,4$ in panels $\mathrm{A}-\mathrm{D}$, respectively. The dates on the $\mathrm{x}$-axis denote the date associated with the centered observation of each rolling window. Each of the figures reports, respectively, results for inflation, real GDP growth, the unemployment rate, and the interest rate. When the test statistic is above the critical value (dotted line), the hypothesis that the forecasts are rational at any given point in time is rejected. Furthermore, the time period associated with the test statistic being above the critical value (dotted line) provides information on when forecasts become irrational. The empirical results clearly show that, for all variables but the interest rates, both the Greenbook/Tealbook as well as the BCEI forecasts were biased in the middle 1990s, although there is less evidence of bias either before then or after the beginning of 2000s. In general, both the Greenbook/Tealbook and the BCEI are irrational at several points throughout the sample - a result that is somewhat robust across forecast horizons. The most important result, however, concerns forecasting the interest rate. Figure 5 clearly shows that the Greenbook/Tealbook nowcast is rational while the BCEI is not. Thus, our results suggest that, indeed, the central bank has insider information regarding the future path of the policy variable, especially in the short-run, that the private sector could be interested in learning. ${ }^{4}$ Similarly, instabilities may also affect the presence of an information channel of monetary policy. For example, whether the central bank has additional information, above and beyond that contained in private forecasts, may depend on the period of time as well. This is why, in contrast to most of the current literature, we employ a testing approach that is fully robust to instabilities. This is important as

\footnotetext{
${ }^{3}$ We estimate eq. (1) in rolling windows of size $m=60$ forecasts and construct Wald test statistics, $W_{t}$, of the null hypothesis $\alpha_{t}=\beta_{t}=0$ for each rolling window estimate $\left(\hat{\alpha}_{t}, \hat{\beta}_{t}\right)$. The Fluctuation Rationality test statistic $W^{*}$ is then given by the largest value of the test statistics across the rolling windows and tests of the null hypothesis robust to instabilities can be carried out using the critical values for survey and model-free forecasts reported by Rossi and Sekhposyan (2016) in Table II. See the next sections for more details.

${ }^{4}$ At longer horizons, even the Greenbook/Tealbook occasionally may lack rationality, while the BCEI is typically more irrational.
} 
Figure 2: Inflation: Fluctuation Rationality Test
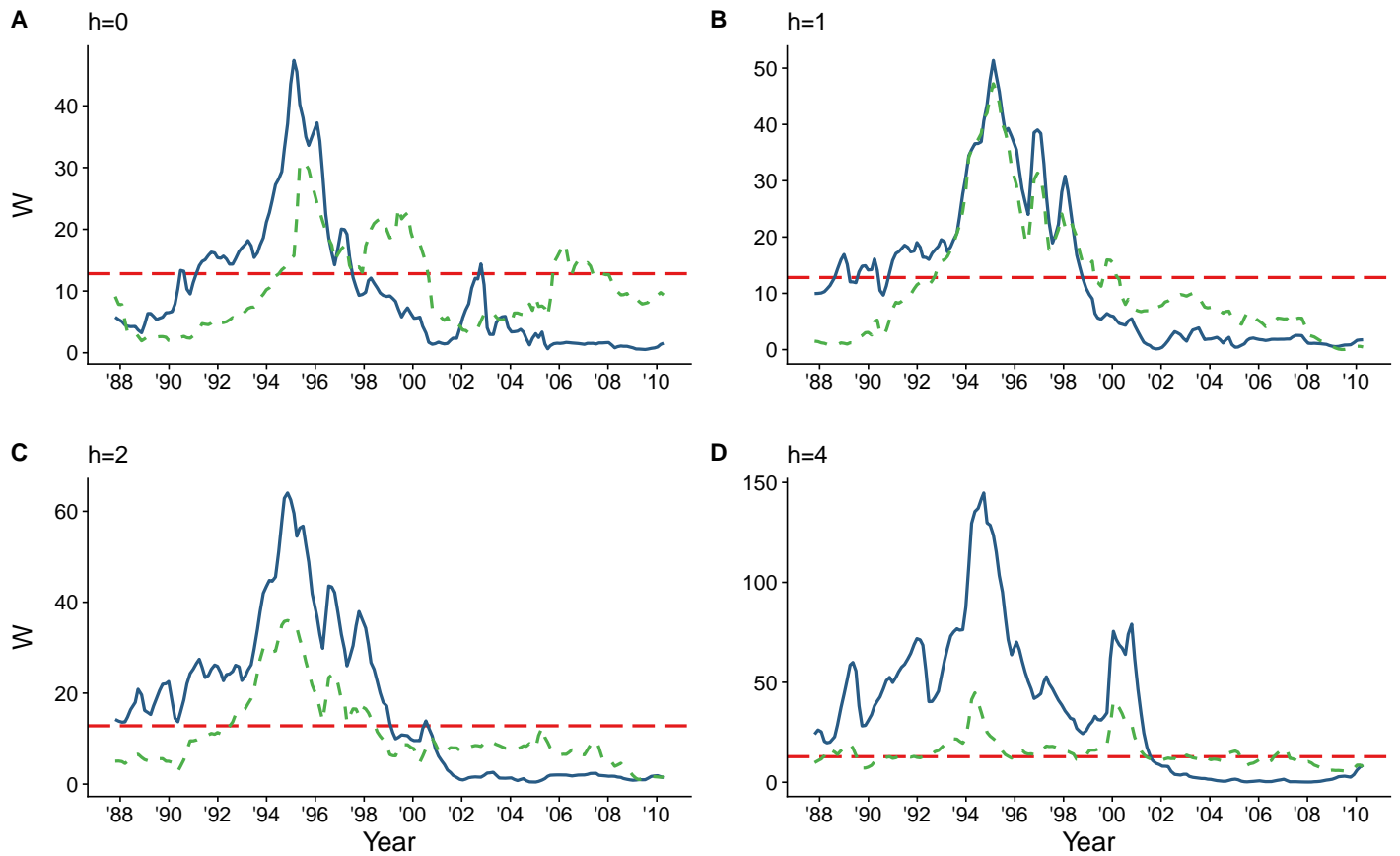

Notes. The figure shows the path of the Fluctuation Rationality test statistic for the BCEI forecasts (blue solid line) and the Greenbook/Tealbook forecasts (green dashed line), obtained with $m=60$ observation rolling window, together with the $5 \%$ critical value (horizontal red dashed line). The dates on the $\mathrm{x}$-axis correspond to the center of the rolling window.

Figure 3: GDP Growth: Fluctuation Rationality Test
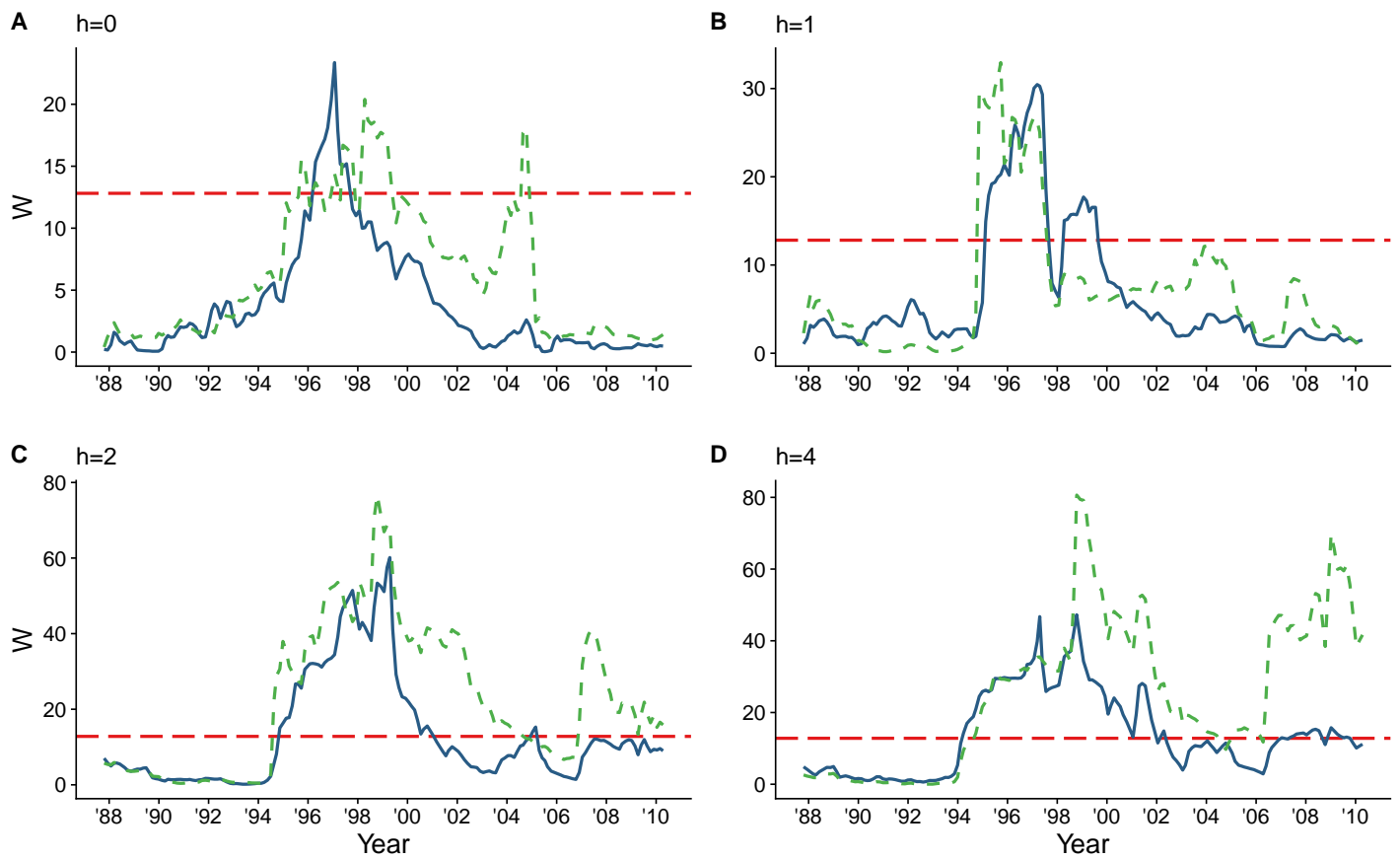

Notes. The figure shows the path of the Fluctuation Rationality test statistic for the BCEI forecasts (blue solid line) and the Greenbook/Tealbook forecasts (green dashed line), obtained with $m=60$ observation rolling window, together with the $5 \%$ critical value (horizontal red dashed line). The dates on the $\mathrm{x}$-axis correspond to the center of the rolling window. 
Figure 4: Unemployment Rate: Fluctuation Rationality Test
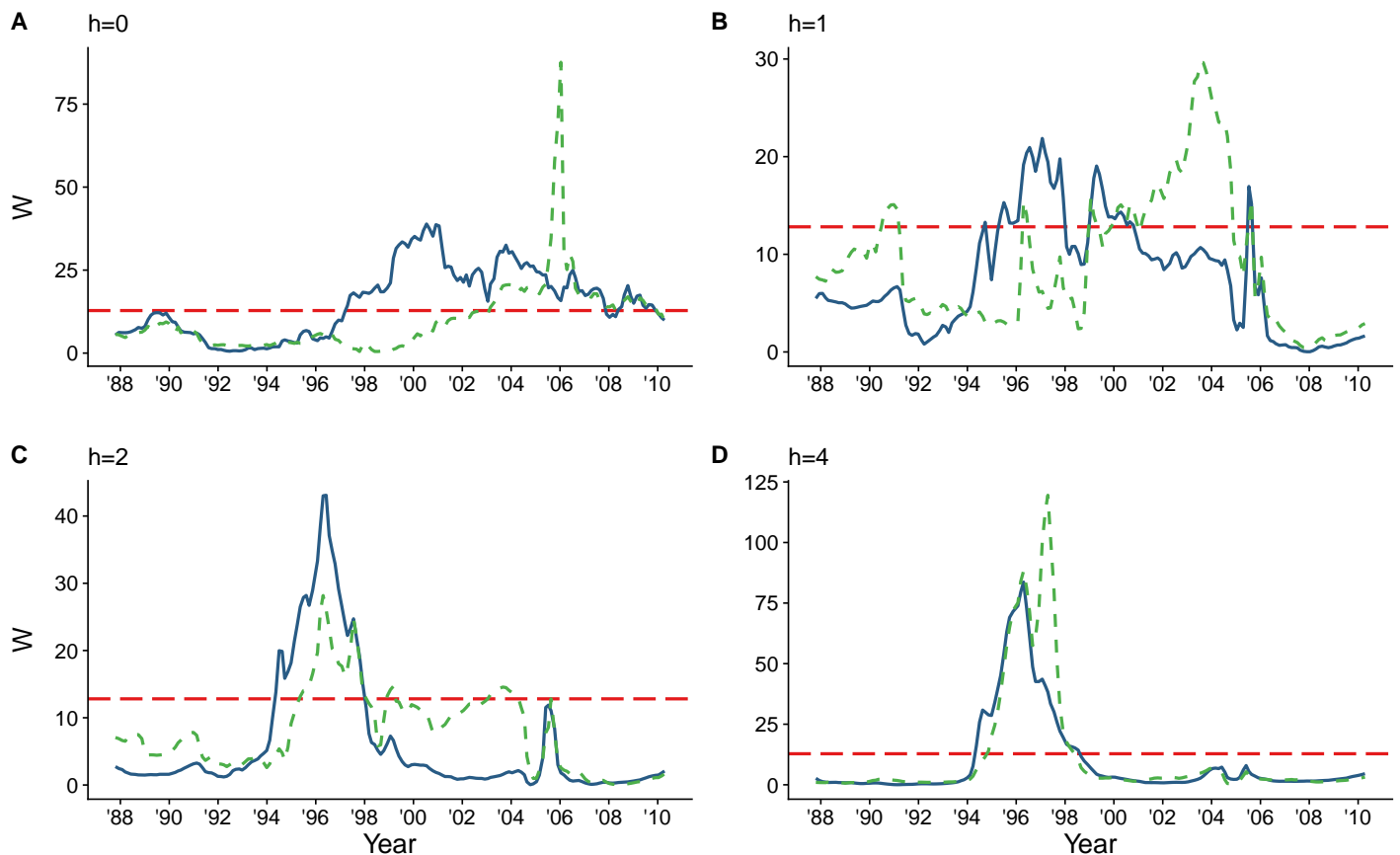

Notes. The figure shows the path of the Fluctuation Rationality test statistic for the BCEI forecasts (blue solid line) and the Greenbook/Tealbook forecasts (green dashed line), obtained with $m=60$ observation rolling window, together with the $5 \%$ critical value (horizontal red dashed line). The dates on the x-axis correspond to the center of the rolling window.

Figure 5: Interest Rate: Fluctuation Rationality Test
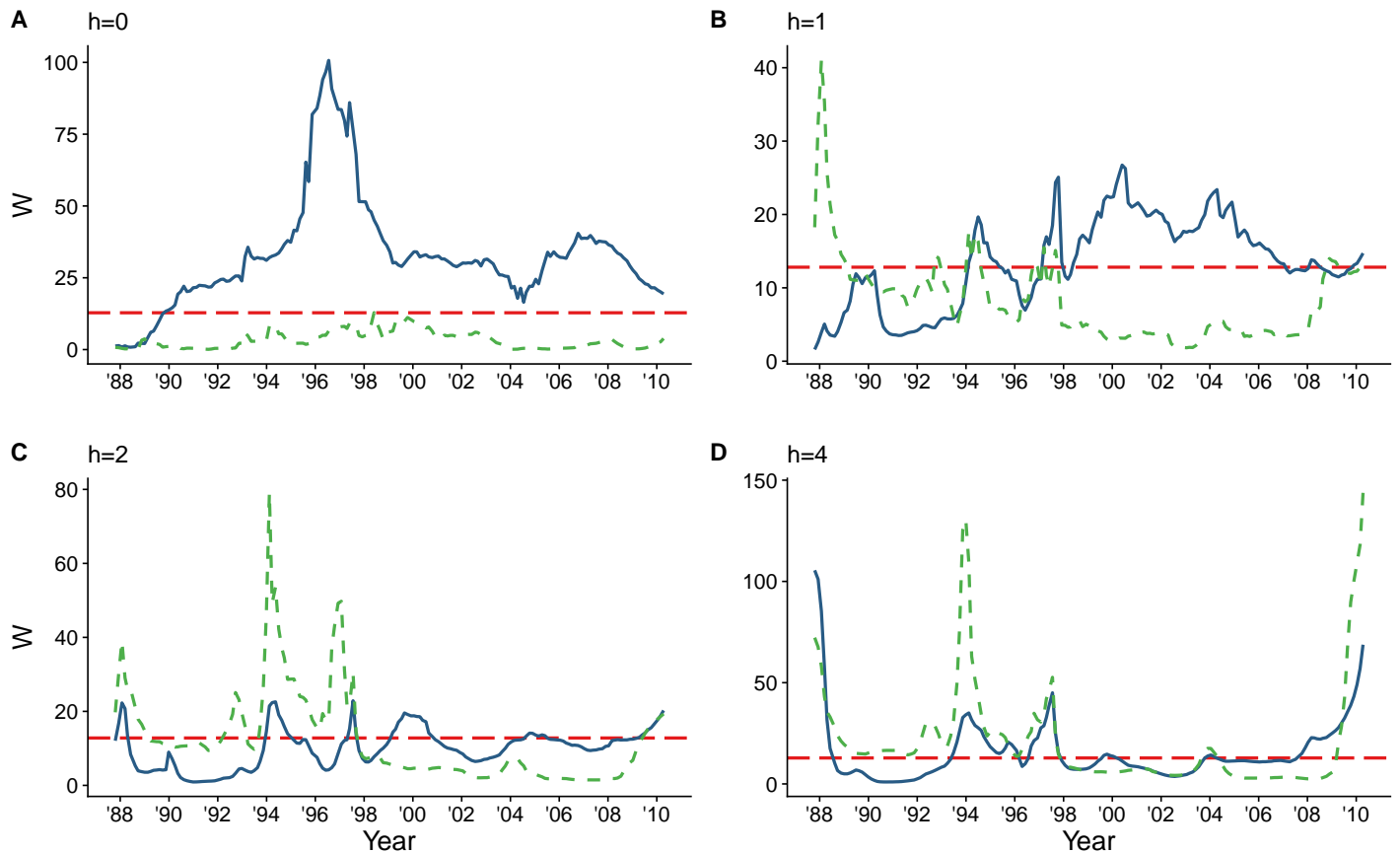

Notes. The figure shows the path of the Fluctuation Rationality test statistic for the BCEI forecasts (blue solid line) and the Greenbook/Tealbook forecasts (green dashed line), obtained with $m=60$ observation rolling window, together with the $5 \%$ critical value (horizontal red dashed line). The dates on the x-axis correspond to the center of the rolling window. 
time-variation in the information advantage might prevent detecting the presence of an information channel.

\section{Data}

To investigate the relationship between the signaling channel of monetary policy and the information advantage of the Federal Reserve staff, we analyze the properties of several key macroeconomic forecasts made by the Federal Reserve and the private sector over a large sample of monetary policy announcement dates. Specifically, we analyze forecasts for inflation, GDP growth, the unemployment rate and the interest rate from two sources, (1) the Blue Chip Economic Indicators, and (2) the projections from the Greenbook/Tealbook of the Federal Reserve Board of Governors. In what follows, we briefly describe the data from each of the sources as well as the necessary data transformations.

\subsection{Monetary policy announcements}

The analyses presented in this paper are based on a comprehensive list of Federal Open Market Committee (FOMC) announcements between February 1984 and July 2013 which we collected from the Historical Archive of the FOMC which is provided by the Board of Governors of the Federal Reserve System. The set of FOMC announcements includes regular monthly FOMC meetings which have an associated Greenbook/Tealbook forecasts, as well as some unscheduled meetings which were followed by a press release. For announcements prior to February 1994, we follow Gürkaynak et al. (2005) and use the dates of open-market operations following an FOMC meeting since the Federal Reserve did not explicitly announce changes in its target for the Federal Funds rate before that date and market participants had to infer the target change indirectly from the openmarket operation. Table 2 in the not-for-publication Appendix A reports the full list of monetary policy announcements.

\subsection{Greenbook/Tealbook forecasts}

As a measure of central bank forecasts we use forecasts of inflation, GDP growth, the unemployment rate and the interest rate from the Greenbook/Tealbook forecasts which are produced by the Federal Reserve Board of Governors' staff prior to each meeting of the FOMC. The Greenbook/Tealbook forecasts are based on a maintained assumption about monetary policy and consist of quarterly forecasts for a variety of economic indicators at several forecast horizons (from contemporaneous up to nine quarters ahead). The projections are made available to the public after a lag of five years. We consider only forecasts of up to five quarters ahead to ensure a sample large enough for inference. For inflation we use the forecasts of the annualized, chain-weighted quarter-over-quarter 
growth in the price index for GDP. Prior to December 1991 these are measured by the price index for the GNP implicit deflator, and between 1992-1995 they are measured by the price index for the GDP implicit deflator. We also consider forecasts of CPI inflation. For GDP growth, we use the forecasts of the annualized, chain-weighted quarter-over-quarter growth in real GDP. Prior to December 1991 these are measured by the real GNP with a fixed weight, between 1992-1995 they are based on real GDP with a fixed weight. For the unemployment rate we use the Greenbook/Tealbook projections for the quarterly average unemployment rate in percentage points. The data for these three forecasts are provided by the Federal Reserve Bank of Philadelphia in the "Greenbook Data Set". Finally, for the interest rate we use the historical projections of the 3-month Treasury bill Rate from the dataset on "Financial Assumptions: Interest Rates and Equity Pieces", also provided by the Federal Reserve Bank of Philadelphia.

\subsection{Blue Chip Economic Indicators}

As a measure of private sector forecasts, we use forecasts of inflation, GDP growth, the unemployment rate and the interest rate from the Blue Chip Economic Indicators (BCEI) which is a monthly commercial survey-based forecast dataset containing consensus forecasts for 16 macroeconomic variables, collected from approximately 50 business economists. For inflation, we use the annualized quarter-over-quarter BCEI consensus forecasts of the GDP deflator price index as well as the Consumer Price Index (CPI). For GDP growth, we use the annualized quarter-over-quarter BCEI consensus forecasts of real GDP growth and for the unemployment rate the BCEI consensus forecast of the quarterly average of the unemployment rate in percentage points. Finally, for the interest rate we use the forecasts of the quarterly average yield on a three-month Treasury bill in percentage points. The BCEI forecasts provide nowcasts as well as forecasts for up to nine quarters ahead. To match the Greenbook/Tealbook forecasts as well as in order to have a reasonable number of observations for inference, we use the BCEI forecasts from January 1980 for up to five quarters ahead. ${ }^{5}$ At the beginning of the sample, the BCEI survey was conducted over three days, beginning on the first working day of each month, which was later shortened to two days. The BCEI consensus (mean) forecasts are released on the 10th of each month. To conduct our analysis at a meeting-level frequency, we match the BCEI forecasts to the FOMC announcements by the following rule. For FOMC meetings taking place after the first 10 days of the month, we use the BCEI forecasts from the month of the meeting. For FOMC meetings taking place within the first 10 days of the month, we use the BCEI forecasts from the month prior to the meeting. Appendix $\mathrm{B}$ presents a robustness check regarding the timing of BCEI and the Federal Reserve's

\footnotetext{
${ }^{5}$ Although the BCEI forecasts are available from August 1976 onwards, the forecasts for the initial four years are for annual changes in key economic variables as opposed to quarterly changes. Therefore, we omit the earlier period.
} 
forecasts.

\subsection{Real-time realizations}

To evaluate the performance of the Greenbook/Tealbook and Blue Chip Economic Indicator forecasts over time, we compare the forecasts of each variable to the corresponding real-time realization. We obtain most of the real-time data from the Philadelphia Fed's "Real-Time Data Set for Macroeconomists" and use the quarterly first-release values where available. For realized inflation, we use the annualized quarter-over-quarter growth rate in the GNP/GDP deflator price index in percentage points, for realized GDP we use the annualized quarter-over-quarter growth rate in real GNP/GDP in percentage points. For the unemployment rate, we use the first release values from the full history of quarterly vintages and monthly observations of the Federal Reserve Bank of Philadelphia, where for each quarter we use the realization from the first month of that quarter. For realizations of the interest rate, we use the 3-month Treasury bill secondary market rate (TB3MS), which we obtain from the FRED database maintained by the Federal Reserve Bank of St. Louis, again taking the observation of the first month in each quarter as the quarterly realization.

\section{Empirical Evidence of the Information Effect and its Evolution Over Time}

The main question we address in this paper is whether the information channel played a role in the transmission of monetary policy in the U.S., and whether its importance evolved over time. According to the "information channel" theory (Nakamura and Steinsson, 2018), in the presence of informational rigidities, informationally constrained private agents could infer from an increase in the central bank's policy rate not only that the central bank is deviating from its rule, but also that it is endogenously responding to stronger than expected future fundamentals. If the latter component is not correctly taken into account, the estimated macroeconomic responses to the monetary policy shock could potentially mix the response to the actual monetary policy shock and to the signal about the future state of the economy.

We start our analysis by checking whether the importance of the information channel has changed over time. We investigate this hypothesis using the information-robust instrument proposed in Miranda-Agrippino and Ricco (2018). The presence of an information channel would explain why the estimates in the literature are inconsistent with standard economic models' predictions. Miranda-Agrippino and Ricco (2018) define the monetary policy shock as the unforecastable shift in the policy instrument that is a complete surprise to market participants. In other words, such shock should not be due to the central bank's 
systematic response to its own macroeconomic forecasts, i.e. the "Greenbook/Tealbook" forecasts in the U.S. Their "information-robust" instrument of monetary policy shock is obtained as the component of high-frequency financial market surprises that is orthogonal to the Federal Reserve's own macroeconomic forecasts as well as to past surprises. In practice, the latter is the residual of a regression of the high-frequency financial market surprises in the Fed Funds futures around Federal Open Market Committee (FOMC) announcements on Greenbook/Tealbook forecasts and forecast revisions. They find that the effects of the robust monetary policy instrument are significantly different from those of the usual monetary policy shock: a contractionary monetary policy shock unambiguously decreases both output and inflation.

In what follows, we first replicate Miranda-Agrippino and Ricco (2018)'s main findings in our full sample using a standard local projection method (Jordà, 2005). Subsequently, we investigate the robustness of the results to the presence of time-variation. ${ }^{6}$ Figure 6 shows that, in the full sample from January 1979 to December 2014, in response to a contractionary monetary policy shock, output increases and unemployment decreases if the shock is based on Gertler and Karadi (2015)'s average monthly market surprise. However, the information-robust instrument proposed by Miranda-Agrippino and Ricco (2018) produces impulse responses that are consistent with economic theory: output decreases and unemployment increases. Additional results using Romer and Romer (2004)'s monetary policy shocks are qualitatively similar, and are reported in Appendix A.

When we allow for time-variation, the results change substantially. ${ }^{7}$ We first concentrate on two sub-samples: the first corresponds to the sub-sample where, as we will argue in the next sections, the empirical evidence in favor of the presence of an information advantage is strongest, which ends in December 2003; the second sub-sample corresponds to the period where the evidence of information advantage is weaker, starting in January 2004. The results for this subsample split are reported in Figure 7. The figure shows a large discrepancy between the information-robust and non-robust methods in the sub-sample up to 2004, while the discrepancy is negligible afterwards. Note how, in the first sub-sample, the response of industrial production to Gertler and Karadi (2015)'s non-robust shocks is particularly problematic. ${ }^{8}$ In the second sub-sample, when the information advantage

\footnotetext{
${ }^{6}$ Miranda-Agrippino and Ricco (2018) use both standard and Bayesian local projections as well as a Bayesian VAR. We use the local projection approach rather than a Bayesian local projection or a Bayesian VAR since the latter require estimation of hyperparameters of the priors on a sub-sample period before the starting date of the sample. It is not possible to choose the estimation sample for the hyperparameters when re-estimating the model over various subsamples in the presence of a possible break without contaminating the sub-samples with obsolete information while remaining with a large enough sample. The standard local projections approach is expected to give wider bands than the Bayesian approaches, but does not require the estimation of hyperparameters.

${ }^{7}$ Note that, while we allow the response to vary over time, the instrument is estimated using the full sample.

${ }^{8}$ Similarly, the response of inflation to the Romer and Romer (2004) shock, reported in appendix A, is problematic.
} 
Figure 6: Informationally Robust Analysis: Full Sample
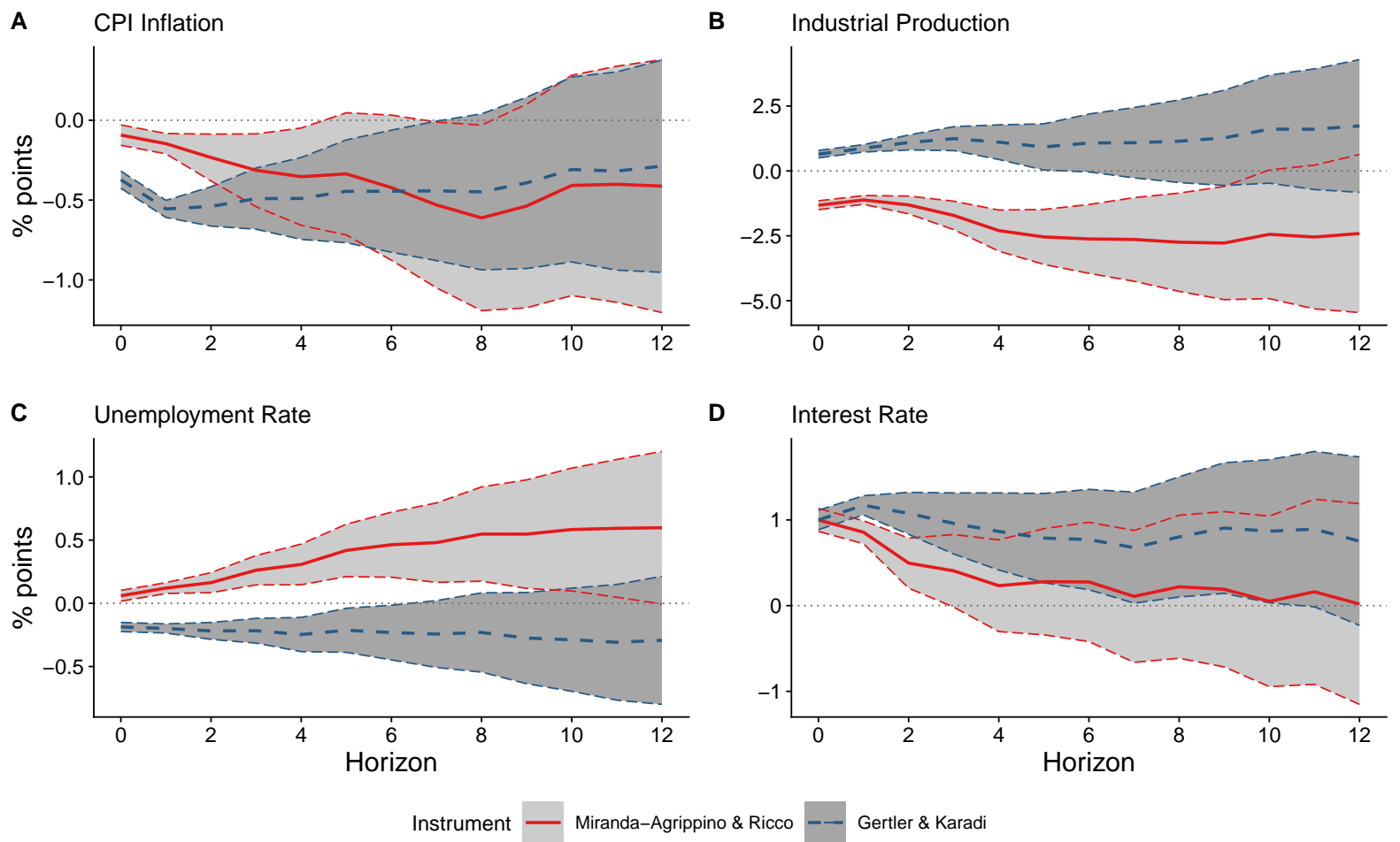

Notes. Responses to monetary policy shocks under different identification assumptions: The blue dashed line denotes Gertler and Karadi (2015)'s average monthly market surprise and the red solid line denotes the informationally robust shock by Miranda-Agrippino and Ricco (2018). The shock is normalized to induce a 100 basis point increase in the 1-year rate. The responses are estimated by local projections on the sample 1979:1 - 2014:12. Shaded areas are 90\% confidence bands based on robust standard errors.

is inexistent, the responses are more similar across information robust and non-robust methods.

To summarize, our analysis suggests that the information channel disappeared in the early 2000. In the next sections, we will investigate this claim in more detail, as well as whether it is related to the fact that the Federal Reserve has lost its informational advantage relative to the private sector, by directly comparing the forecasts of the private sector with those of the Federal Reserve staff.

\section{Does the Federal Reserve Have an Information Ad- vantage Relative to the Private Sector?}

This section revisits the empirical evidence on whether the Federal Reserve has more information relative to the private sector when forecasting macroeconomic variables and investigates whether such information advantage is present in the most recent period. To assess whether the Federal Reserve has an information advantage over the private 
Figure 7: Informationally Robust Analysis: 1979-2003 and 2004-2014 subsamples

A

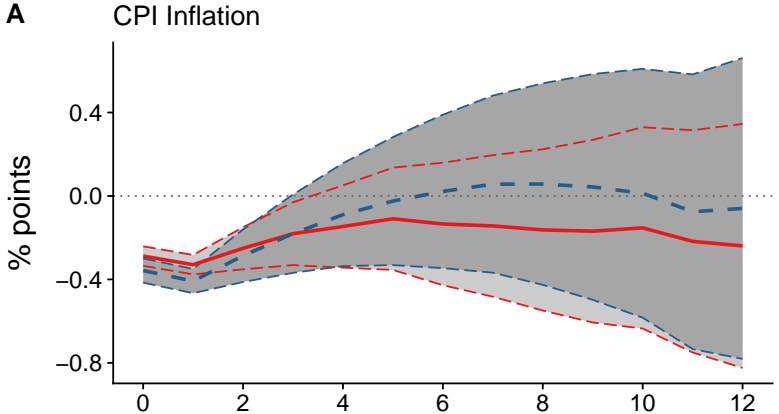

B

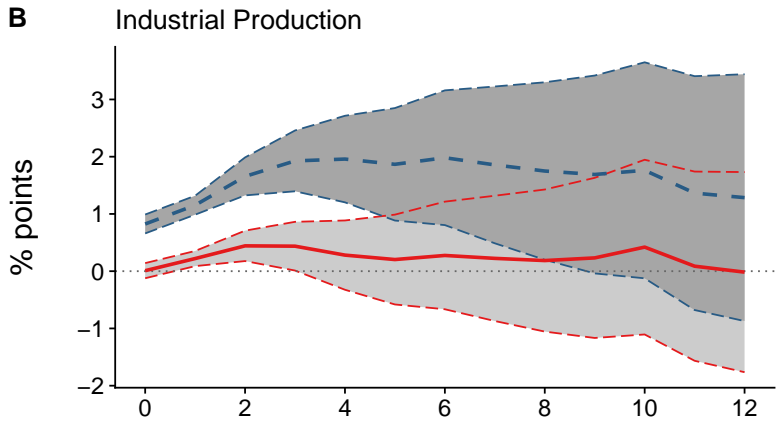

C Unemployment Rate

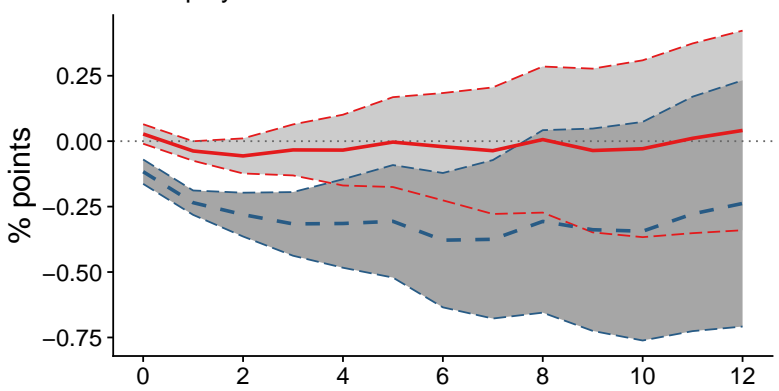

D

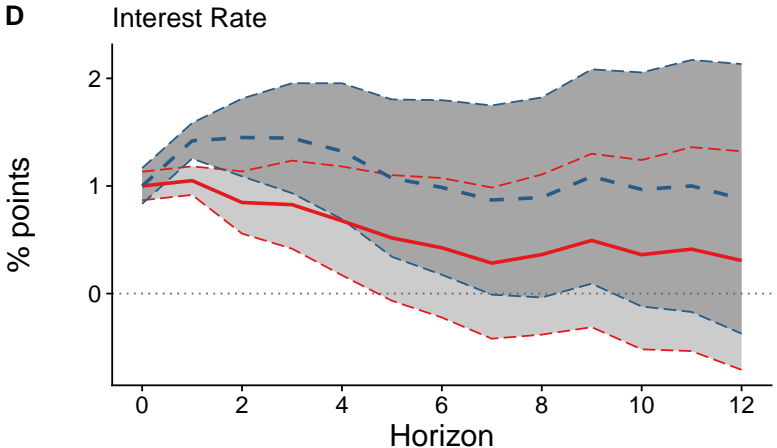

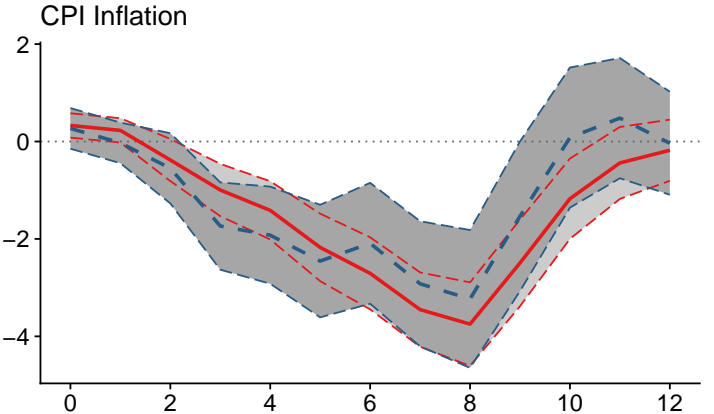

Industrial Production
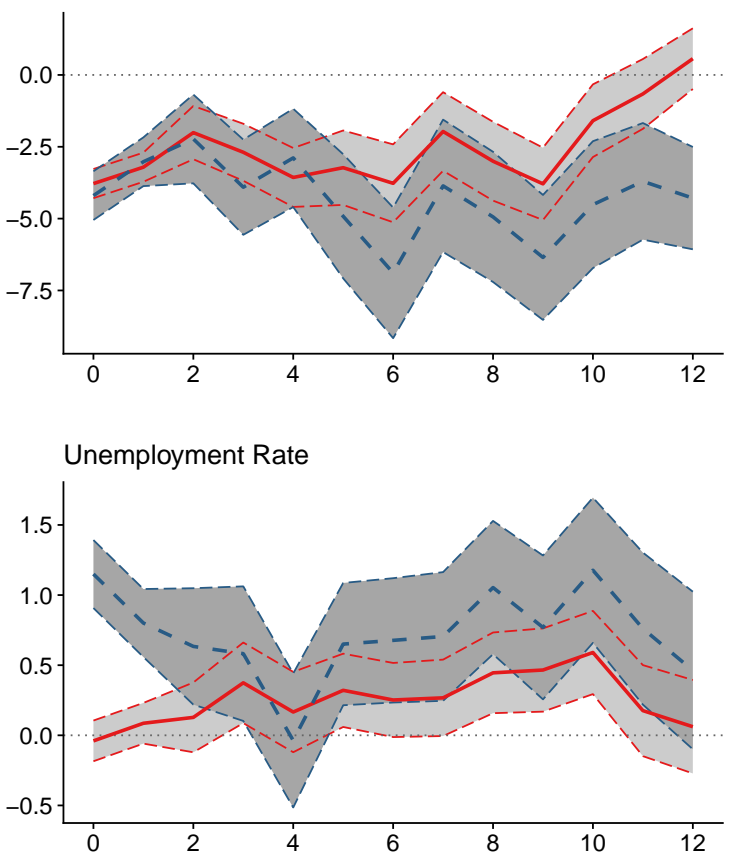

Interest Rate

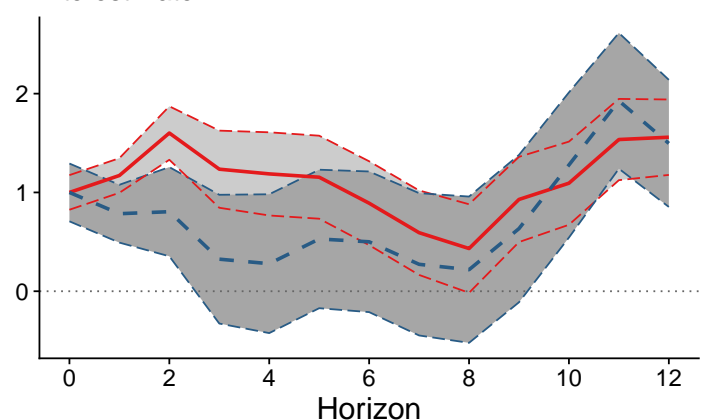

Gertler \& Karadi

Notes. Responses to monetary policy shocks in two sub-samples: 1/1/1979-12/31/2003 (left panel) and 1/1/2004-31/12/2014 (right panel). The responses are obtained under different identification assumptions: The blue dashed line denotes Gertler and Karadi (2015)'s average monthly market surprise and the red solid line denotes the informationally robust shock by Miranda-Agrippino and Ricco (2018). The shock is normalized to induce a 100 basis point increase in the 1-year rate. The responses are estimated by local projections. Shaded areas are $90 \%$ confidence bands based on robust standard errors. 
sector in forecasting a variable $x$, consider the following regression:

$$
x_{t+h}-x_{t+h \mid t}^{B C E I}=\delta+\beta_{G B} x_{t+h \mid t}^{G B}+\beta_{B C E I} x_{t+h \mid t}^{B C E I}+\eta_{t+h},
$$

where $x_{t+h \mid t}^{G B}$ is the Greenbook/Tealbook forecast at horizon $h, x_{t+h \mid t}^{B C E I}$ is the Blue-Chip consensus forecast at horizon $h$ and $x_{t+h}$ denotes the real-time realization. Central bank's forecasts provide additional information above and beyond that in BCEI survey's forecasts if $\beta_{G B}$ is different from zero. Note that Romer and Romer (2000) estimate a slightly different regression, which is

$$
x_{t+h}=\delta+\beta_{G B} x_{t+h \mid t}^{G B}+\beta_{B C E I}^{*} x_{t+h \mid t}^{B C E I}+\eta_{t+h}
$$

We implement the same regression except that we subtract the BCEI forecasts on both sides of the equation and let $\beta_{B C E I}=\beta_{B C E I}^{*}-1$. We consider forecasts of a comprehensive list of core macroeconomic variables for $x_{t}$, such as real GDP growth, GDP deflator-based inflation, the unemployment rate and the interest rate.

The goal of the analysis is to assess whether the Federal Reserve forecasts, $x_{t+h}^{G B}$, are useful beyond those of the private sector, $x_{t+h}^{B C E I}$. This is the case if and only if $\beta_{G B} \neq 0$. In order to be robust to the presence of possible time-variation in $\beta_{G B}$, we use the Fluctuation Rationality test proposed by Rossi and Sekhposyan (2016). Specifically, we estimate eq. (2) in rolling windows of $m=60$ forecasts and construct t-statistics $\left(t_{G B}\right)$ of the null hypothesis $\beta_{G B}=0$ for each rolling window estimate $\hat{\beta}_{G B}$. The information-advantage Fluctuation test statistic $t_{G B}^{*}$ is the largest absolute value of the test statistics across the rolling windows. Tests of the hypothesis $\beta_{G B}=0$ robust to instabilities can be carried out using the critical values for survey and model-free forecasts reported in Table II of Rossi and Sekhposyan (2016).

Figures 8 to 11 plot $t_{G B}$ over time together with the $5 \%$ critical values for forecast horizons $h=0,1,2,4$ quarters. We report results for inflation, GDP growth, unemployment and the interest rate. The dates on the $\mathrm{x}$-axis denote the date associated with the centered observation of each rolling window.

Let's first focus on the information advantage for the medium horizon (one-year-ahead, i.e. $\mathrm{h}=4$ ), depicted in the bottom right panels in Figures 8 to 11. Figure 8 shows that the information advantage in predicting inflation in the medium-run disappeared in the early 1990s. As for GDP growth, Figure 9 shows that the information advantage was also not present in our sample, that starts in the late 1980s. The results are very different for shorter horizons, in which case the information advantage disappeared in the early 2000s for both variables. In particular, the information advantage simultaneously disappeared in the nowcast $(\mathrm{h}=0)$ since 2005 simultaneously for both variables. The information advantage at the one-month forecast horizon depends on the variable: in the case of real GDP growth forecasts, the advantage disappeared in the mid-2000s, when the Fed almost 
never had any informational advantage for longer term forecasts (two- and four-quarterahead). In the case of inflation forecasts, the information advantage disappeared at the beginning of 2000 for both the one- and two-quarter-ahead forecasts. D'Agostino and Whelan (2008) similarly found a decrease in longer horizon predictability in output growth and inflation; our results, however, highlight that even shorter horizon predictability disappeared, although only more recently.

Figure 11 sheds light on the possible reasons behind the disappearance of the Fed's information advantage. The figure shows that, when forecasting the short-term interest rate, the Fed lost its information advantage in mid-2000s at one-, two- and four-quarter ahead prediction horizons, while it has not had any information advantage for the nowcast since the early 1990s. This disappearance of information advantage is related to the improved communication strategies implemented by the Federal Reserve. The public has had access to the FOMC minutes since February, 1993, with the lag in the release of the minutes becoming shorter from December of 2004 onwards. Furthermore, the Federal Reserve has been releasing FOMC statements since February 1994. On the other hand, the decrease in short-term predictability since 2004 is mirrored by a decrease in one- to four-quarter-ahead predictability of the short-term interest rate. The latter is associated with the explicit introduction of forward guidance in monetary policy at a time when the Fed started communicating its expectations about its own policy decisions, as documented in several studies, most notably Lunsford (2018).

Regarding unemployment, the Fed has an advantage for some periods in time, including the early 1990s, but the advantage disappeared in mid-2000s for longer-term forecasts, while it is still present in shorter-term forecasts, even if sporadically.

In summary, our analysis suggests that the information advantage is not present in the most recent data, either because it disappeared in the mid-2000s or because it was never there in our sample. The results are quite consistent across all target variables and different horizons. Overall, the results are quite striking and allow us to conclude that BCEI and Greenbook/Tealbook forecasts have become similar to each other in terms of their information content over time. There is no information advantage when forecasting at any horizon at least since the mid-2000s, apart from the case of unemployment forecasts in the very short-run. 
Figure 8: Inflation: Information-Advantage Fluctuation Test

A
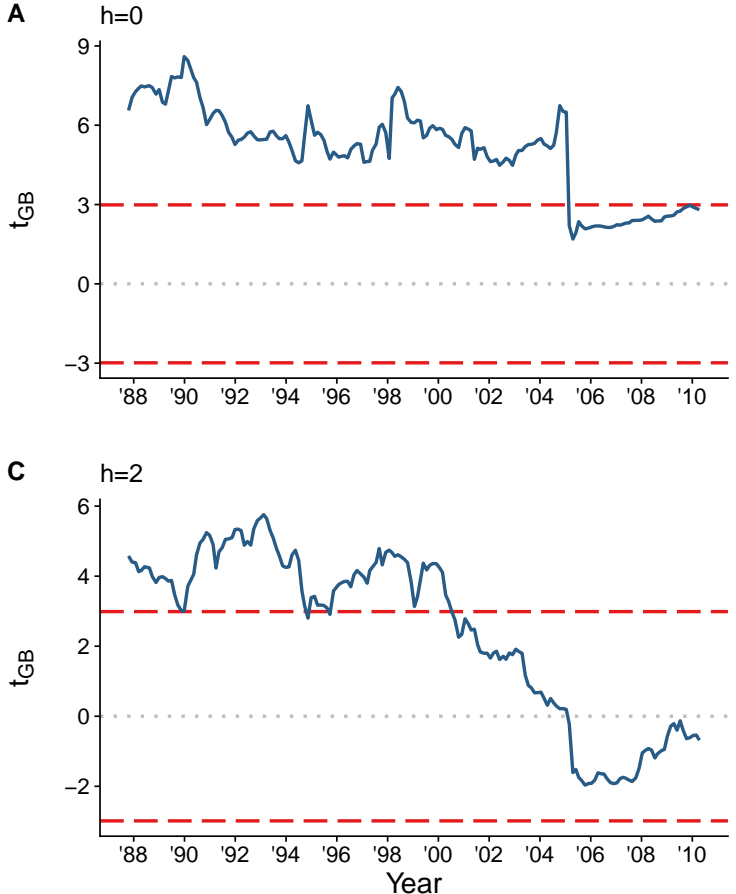

B

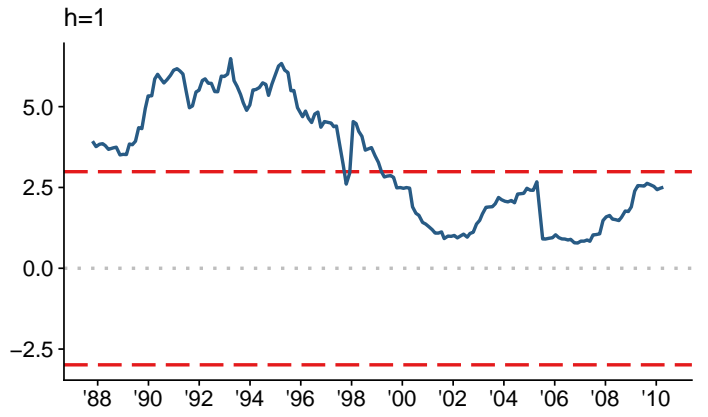

D

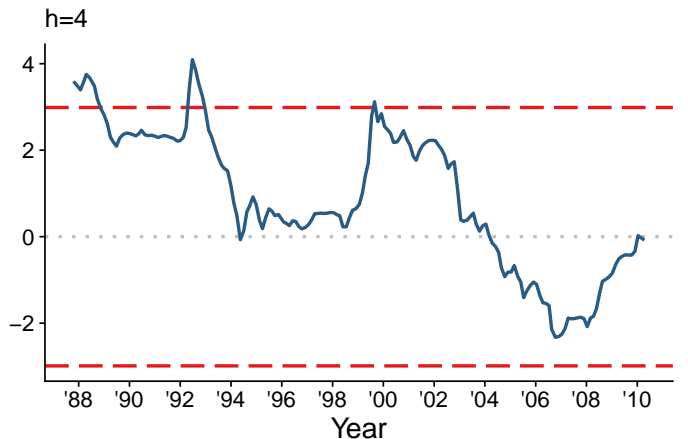

Notes. The solid blue line denotes the Fluctuation test statistic $t_{G B}$ estimated in rolling-windows $(m=60)$ centered around the date on the x-axis. The test rejects for test statistic values outside the $5 \%$ critical value bands (red dashed lines).

Figure 9: GDP Growth: Information-Advantage Fluctuation Test

A

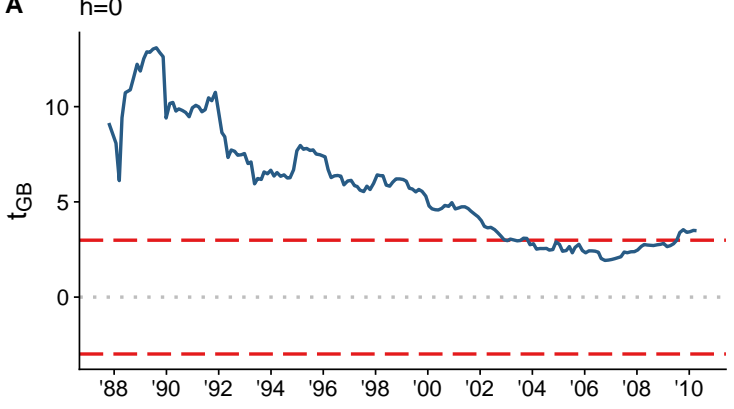

B

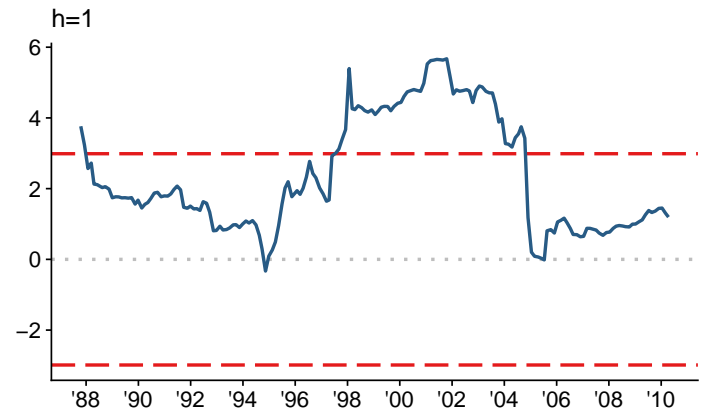

D $\mathrm{h}=4$

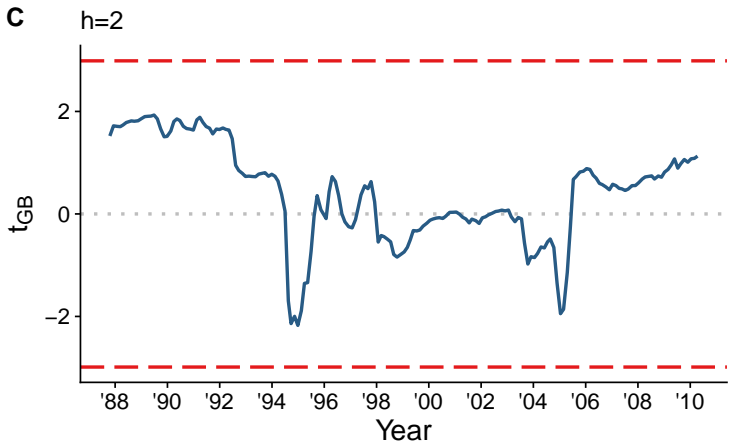

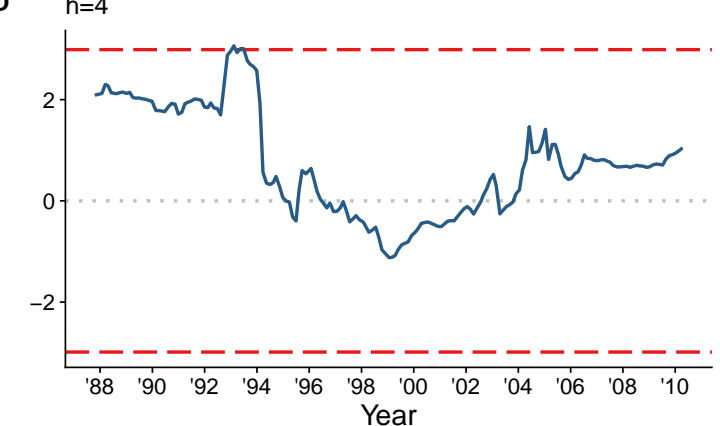

Notes. The solid blue line denotes the Fluctuation test statistic $t_{G B}$ estimated in rolling-windows $(m=60)$ centered around the date on the x-axis. The test rejects for test statistic values outside the $5 \%$ critical value bands (red dashed lines). 
Figure 10: Unemployment Rate: Information-Advantage Fluctuation Test
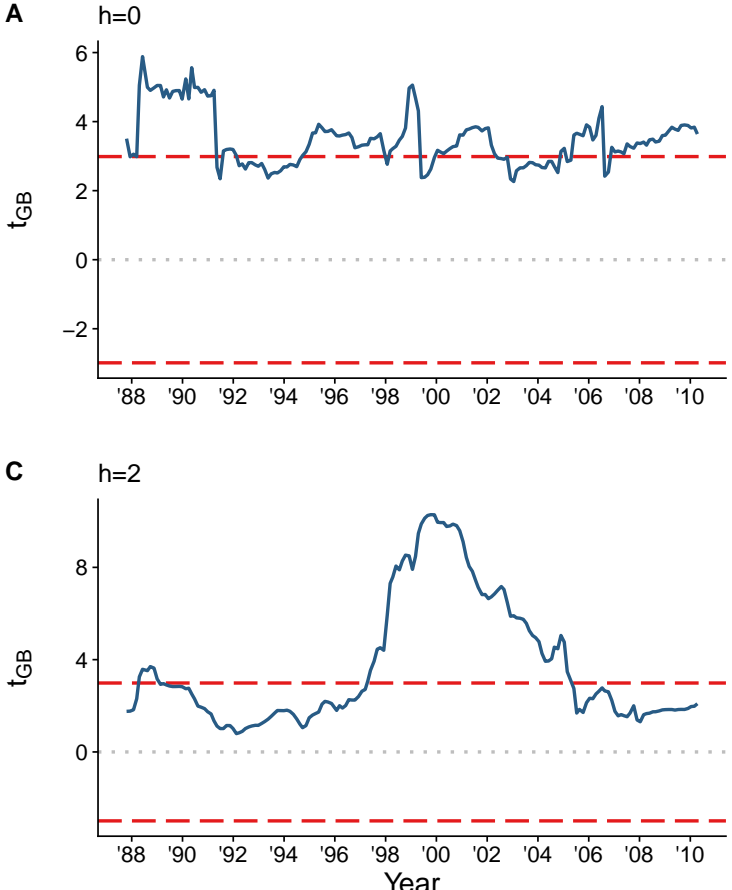

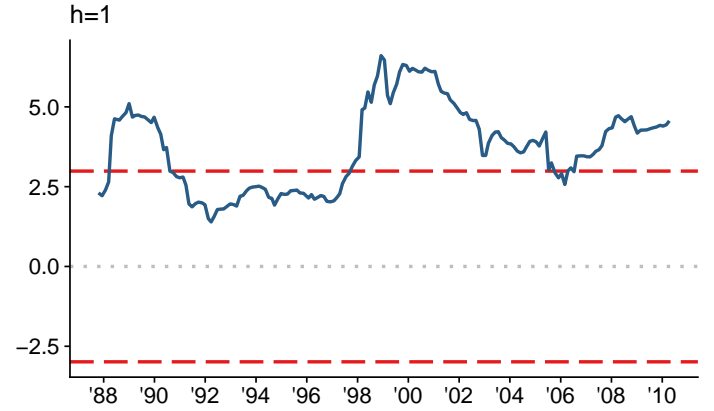

D

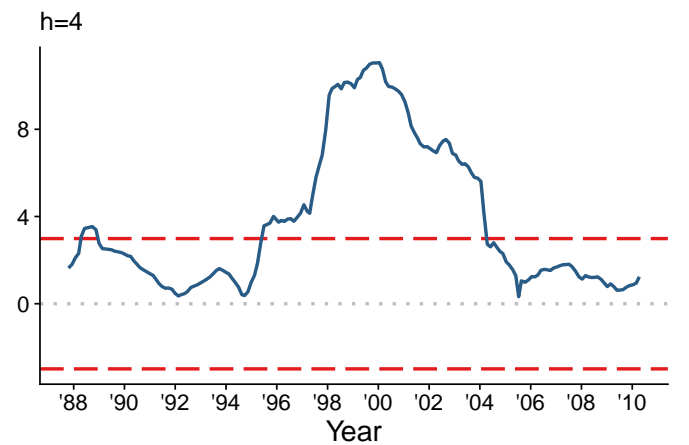

Notes. The solid blue line denotes the Fluctuation test statistic $t_{G B}$ estimated in rolling-windows $(m=60)$ centered around the date on the x-axis. The test rejects for test statistic values outside the $5 \%$ critical value bands (red dashed lines).

Figure 11: Interest Rate: Information-Advantage Fluctuation Test

A
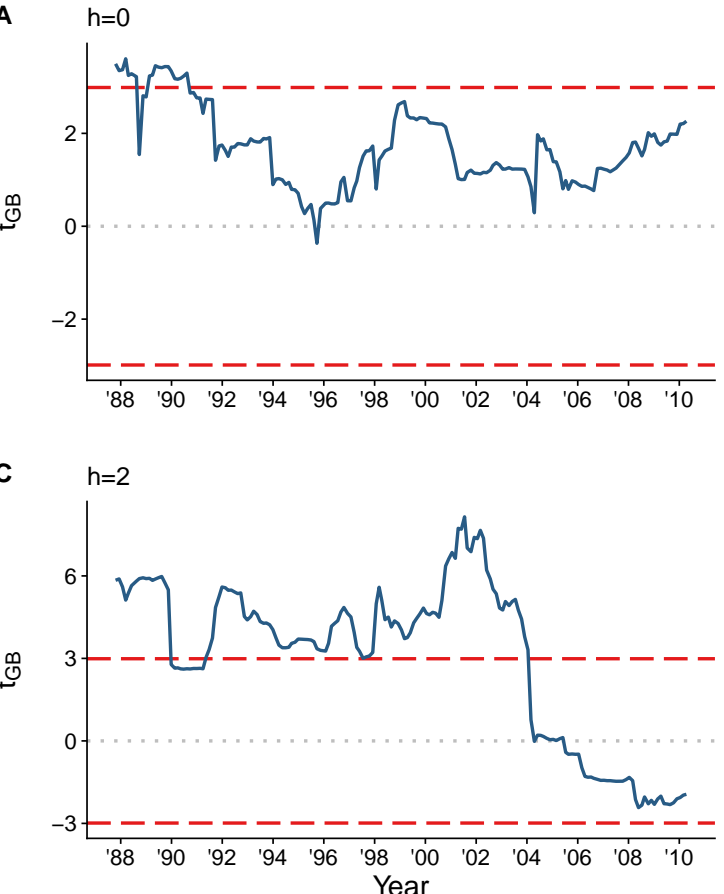

B $\quad h=1$

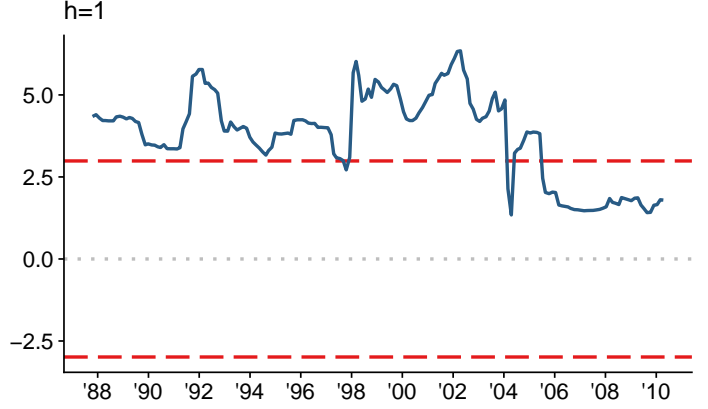

D

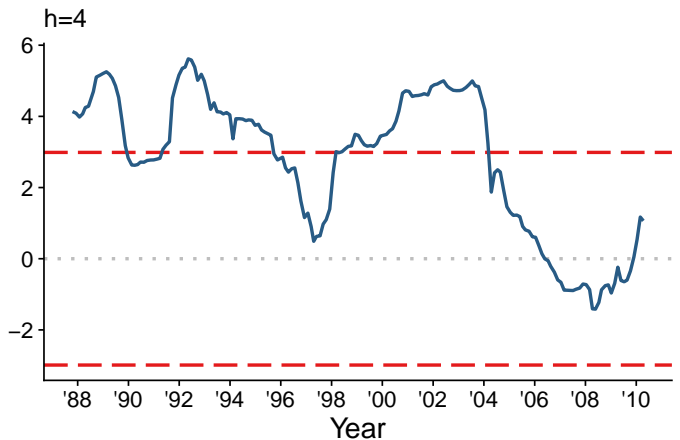

Notes. The solid blue line denotes the Fluctuation test statistic $t_{G B}$ estimated in rolling-windows $(m=60)$ centered around the date on the x-axis. The test rejects for test statistic values outside the $5 \%$ critical value bands (red dashed lines). 


\section{Do Private Forecasters React to Information Shocks, and How?}

Finally, we empirically characterize the dynamic response of private macroeconomic forecasts to the Federal Open Market Committee (FOMC) forward guidance and investigate whether professional forecasters react to information conveyed by FOMC announcements over and above the change in the target rate. We do so by estimating the response of revisions in the Blue-Chip consensus forecasts to a measure of the informational content of FOMC announcements by running the following regression inspired by Campbell et al. (2012) and Campbell et al. (2017). The latter find that unemployment forecasts react negatively and inflation forecasts react positively to information associated with future tightening of monetary policy. Since these responses exhibit opposite signs to those predicted by a standard New Keynesian model, they conclude that the empirical evidence supports the existence of an information channel and that professional forecasters believe that FOMC policy surprises contain useful and otherwise unavailable information to the public.

Throughout, we estimate the following regression:

$$
\Delta x_{t+h \mid t}^{B C E I}=\alpha+\beta_{1} \epsilon_{t}^{\text {target }}+\beta_{2} \epsilon_{t}^{\text {path }}+\varepsilon_{t+h}
$$

where $\Delta x_{t+h \mid t}^{B C E I}$ denotes the revision of the Blue-Chip Economic Indicators' consensus forecasts at horizon $h$ between FOMC meetings. ${ }^{9}$ In the above regression, similar to that in Campbell et al. (2012), $\epsilon_{t}^{\text {target }}$ and $\epsilon_{t}^{\text {path }}$ are the target and path factors from Gürkaynak et al. (2005). For our analysis, we construct both factors recursively in real-time using only information that was available at the time the forecasts were made. ${ }^{10}$ We estimate eq. (4) for our sample of monetary policy announcements described in Section 3. As in Campbell et al. (2012), we exclude the QE1 announcement on March 18, 2009 because of its large effect on the markets.

We start by replicating the analysis in Campbell et al. (2012) and Campbell et al. $(2017)^{11}$. We first analyze whether professional forecasters believe that the Federal Reserve conveys information about the state of the economy and future monetary policy in its announcements by separately analyzing the pre- and post-crisis responses of revisions in the BlueChip consensus forecast to the informational content of monetary-policy announcements. For each subsample, we construct the factors in real-time i.e. using only observations

\footnotetext{
${ }^{9}$ For each meeting, variable and forecast horizon, we calculate the revision in the Blue-Chip forecast as the difference between the Blue-Chip forecast following the meeting and the one just prior to the meeting. When the target dates of those forecasts are unequal, we use the previous BCEI forecast at one horizon larger, to keep the target date fixed when calculating the revision.

${ }^{10}$ Our main findings presented in this section are robust to constructing the factors based on data available in each subsample/rolling window only. The results for these regressions are available on request.

${ }^{11}$ The replication results are available on request.
} 
between the beginning of our sample and the last observation in the sub-sample. In our analysis, we also extend the data to other forecasts and a longer sample. In particular, we extend the analysis to a larger sample that includes FOMC announcements and forecasts between February 1990 and December 2013.

Table 1 shows that, indeed, contractionary monetary policy shocks that increase either the target or the path factors result in output and inflation increases and a decrease in unemployment. These results contradict the predictions from typical macroeconomic models. This sub-sample analysis, similar to those typically conducted in the literature, however, might not be robust to the presence of time-variation in the response of private forecasts to the information content of monetary policy announcements. The problem would arise if the time-variation appears at a time different from that identified by the sub-samples in Campbell et al. (2012).

To analyze whether the results are robust to the presence of general forms of timevariation, we conduct a rolling-window analysis using the Fluctuation test. We estimate the regression in eq. (4) in rolling windows over our full sample of announcements, which spans February, 1990 - December, 2013, moving ahead one announcement at a time. The window size is $m=60$ announcements which corresponds to approximately 20 quarters of observations. ${ }^{12}$

Figures 12-15 depict the sequence of the Fluctuation test statistics on $\beta_{1}$ or $\beta_{2}$ being equal to zero, respectively, together with the $5 \%$ critical value line. The results clearly suggest that, when survey forecast updates significantly react to monetary policy shocks, this typically happens in the earlier part of the sample. For none of the variables and no forecast horizon we detect any significant evidence of a reaction in the most recent years. These episodic incidents drive the results reported in Table 1, where the full-sample is divided to pre-financial crisis and post-financial crisis episodes. On the other hand, there is significant evidence that the interest rate forecasts provided by the private forecasters are affected significantly by the level factor associated with monetary policy.

\footnotetext{
${ }^{12}$ Since for some months there are multiple announcements, the window dates are not equally spaced. However, each rolling window contains a fixed fraction of the overall available observations so that we can apply the framework of Rossi and Sekhposyan (2016).
} 
Table 1: Regression estimating private forecast responses to Target and Path factors

Feb 1990 to Jun 2007 Aug 2007 to Dec 2013

\begin{tabular}{|c|c|c|c|c|c|c|}
\hline$h$ & Target & Path & $R^{2}$ & Target & Path & $R^{2}$ \\
\hline \multicolumn{7}{|c|}{ CPI Inflation } \\
\hline 0 & $\begin{array}{c}0.17 \\
(0.35)\end{array}$ & $\begin{array}{c}0.54^{* * *} \\
(0.19)\end{array}$ & 0.03 & $\begin{array}{c}1.61 \\
(1.07)\end{array}$ & $\begin{array}{c}2.93^{* *} \\
(1.21)\end{array}$ & 0.19 \\
\hline 1 & $\begin{array}{l}0.23^{*} \\
(0.13)\end{array}$ & $\begin{array}{l}-0.02 \\
(0.06)\end{array}$ & 0.01 & $\begin{array}{c}0.29 \\
(0.29)\end{array}$ & $\begin{array}{l}0.76^{* *} \\
(0.31)\end{array}$ & 0.11 \\
\hline 2 & $\begin{array}{c}0.12 \\
(0.08)\end{array}$ & $\begin{array}{l}-0.03 \\
(0.06)\end{array}$ & 0.01 & $\begin{array}{c}0.03 \\
(0.12)\end{array}$ & $\begin{array}{c}0.02 \\
(0.06)\end{array}$ & 0.00 \\
\hline 3 & $\begin{array}{c}0.06 \\
(0.10)\end{array}$ & $\begin{array}{c}0.15 \\
(0.19)\end{array}$ & 0.03 & $\begin{array}{l}-0.03 \\
(0.06)\end{array}$ & $\begin{array}{c}0.07 \\
(0.07)\end{array}$ & 0.01 \\
\hline
\end{tabular}

GDP growth

\begin{tabular}{ccccccc}
\hline 0 & $1.18^{* * *}$ & $0.34^{*}$ & 0.05 & $1.77^{* *}$ & $1.03^{* *}$ & 0.10 \\
& $(0.45)$ & $(0.21)$ & & $(0.70)$ & $(0.46)$ & \\
1 & $0.54^{* *}$ & $0.30^{*}$ & 0.04 & $1.30^{* *}$ & 0.38 & 0.07 \\
& $(0.24)$ & $(0.15)$ & & $(0.60)$ & $(0.25)$ & \\
2 & $0.70^{*}$ & 0.11 & 0.05 & -0.05 & $0.29^{*}$ & 0.02 \\
& $(0.42)$ & $(0.11)$ & & $(0.24)$ & $(0.15)$ & \\
3 & -0.07 & 0.04 & 0.00 & -0.05 & -0.03 & 0.00 \\
& $(0.12)$ & $(0.07)$ & & $(0.20)$ & $(0.14)$ &
\end{tabular}

Unemployment Rate

\begin{tabular}{ccccccc}
\hline 0 & $-0.17^{*}$ & -0.07 & 0.03 & -0.32 & -0.06 & 0.03 \\
& $(0.10)$ & $(0.06)$ & & $(0.22)$ & $(0.11)$ & \\
1 & $-0.21^{* *}$ & $-0.13^{*}$ & 0.04 & -0.43 & -0.14 & 0.04 \\
& $(0.09)$ & $(0.07)$ & & $(0.27)$ & $(0.13)$ & \\
2 & $-0.27^{* *}$ & $-0.15^{*}$ & 0.05 & -0.52 & -0.22 & 0.04 \\
& $(0.11)$ & $(0.08)$ & & $(0.33)$ & $(0.15)$ & \\
3 & $-0.27^{* * *}$ & $-0.13^{*}$ & 0.05 & -0.54 & -0.25 & 0.04 \\
& $(0.10)$ & $(0.07)$ & & $(0.36)$ & $(0.17)$ &
\end{tabular}

Interest Rate

\begin{tabular}{ccccccc}
\hline 0 & $0.77^{* * *}$ & 0.13 & 0.12 & $1.28^{* * *}$ & 0.11 & 0.23 \\
& $(0.17)$ & $(0.10)$ & & $(0.39)$ & $(0.11)$ & \\
1 & $0.92^{* * *}$ & 0.21 & 0.12 & $1.76^{* * *}$ & 0.06 & 0.29 \\
& $(0.22)$ & $(0.13)$ & & $(0.51)$ & $(0.12)$ & \\
2 & $0.86^{* * *}$ & $0.31^{* *}$ & 0.12 & $1.81^{* * *}$ & 0.09 & 0.28 \\
& $(0.23)$ & $(0.14)$ & & $(0.55)$ & $(0.14)$ & \\
3 & $0.82^{* * *}$ & $0.31^{* *}$ & 0.11 & $1.74^{* * *}$ & 0.16 & 0.22 \\
& $(0.20)$ & $(0.14)$ & & $(0.57)$ & $(0.15)$ & \\
\hline
\end{tabular}

Notes. The table shows the results from estimating the private forecast response regression (4) on the subsamples indicated at the top of the table. Standard-errors are based on a Newey-West heteroskedasticityand autocorrelation-robust estimator with $p$ lags where $p=\left\lfloor T^{1 / 4}\right\rceil$. 
Figure 12: CPI Inflation: Forecast Response Fluctuation Test
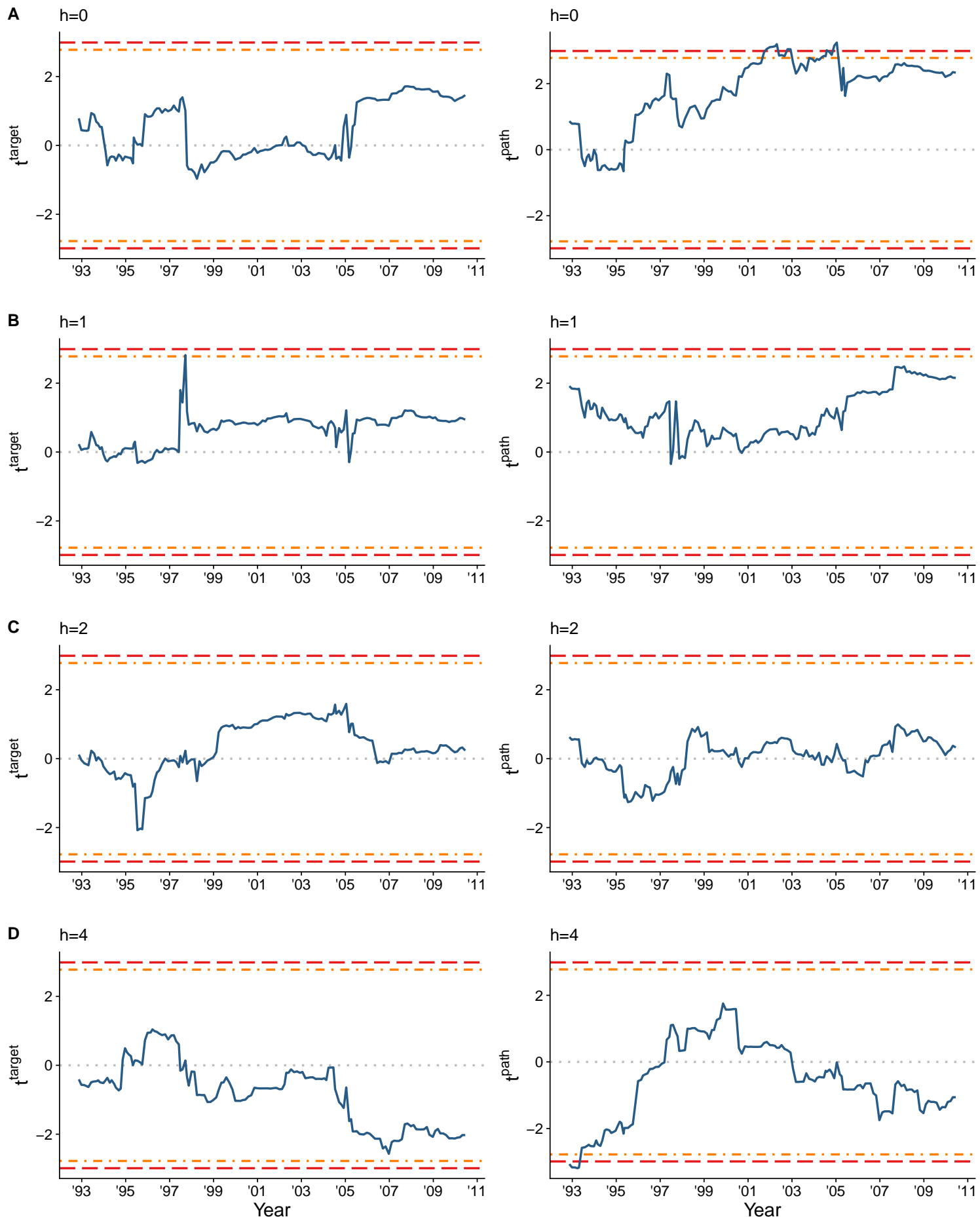

Notes. The figures show the path of the Fluctuation test statistics on the target factor (left panel) and path factor (right panel). The tests reject for test statistic values outside the $5 \%$ (red dashed lines) and $10 \%$ (orange dash-dotted line) critical value bands. 
Figure 13: GDP Growth: Forecast Response Fluctuation Test

A
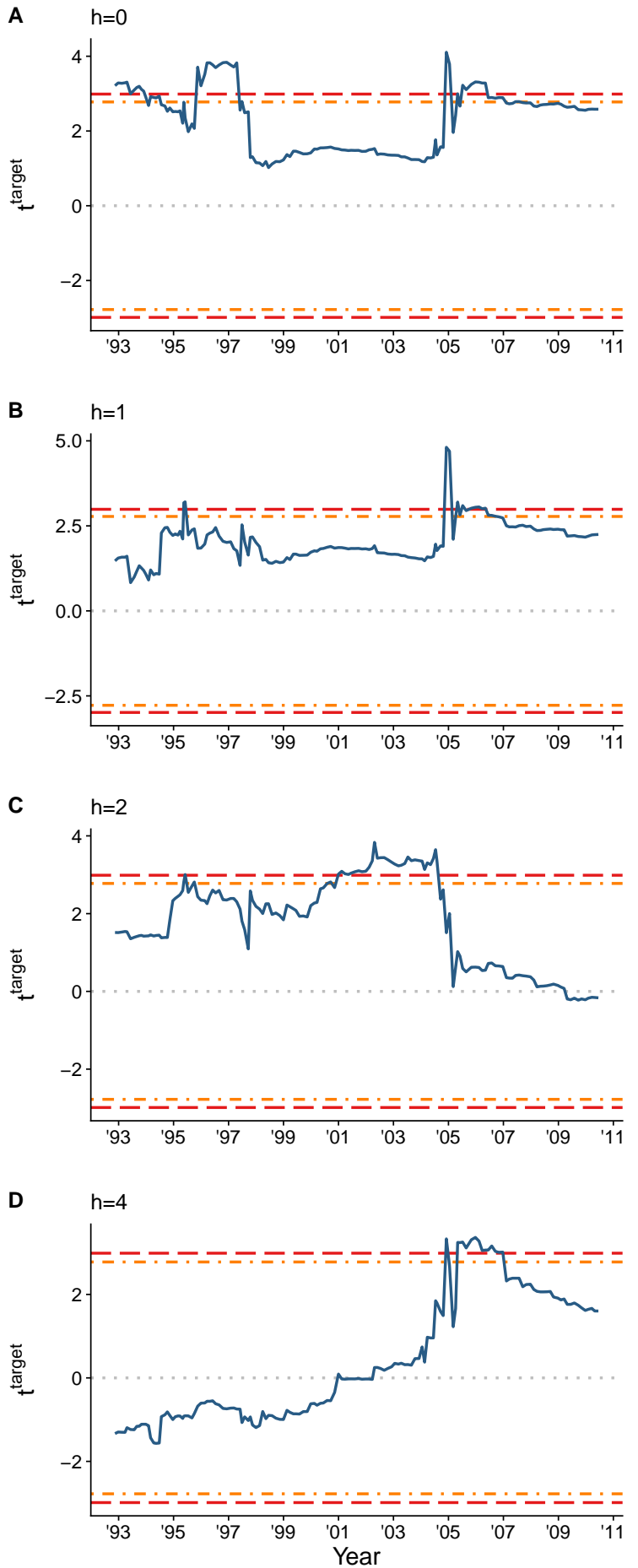
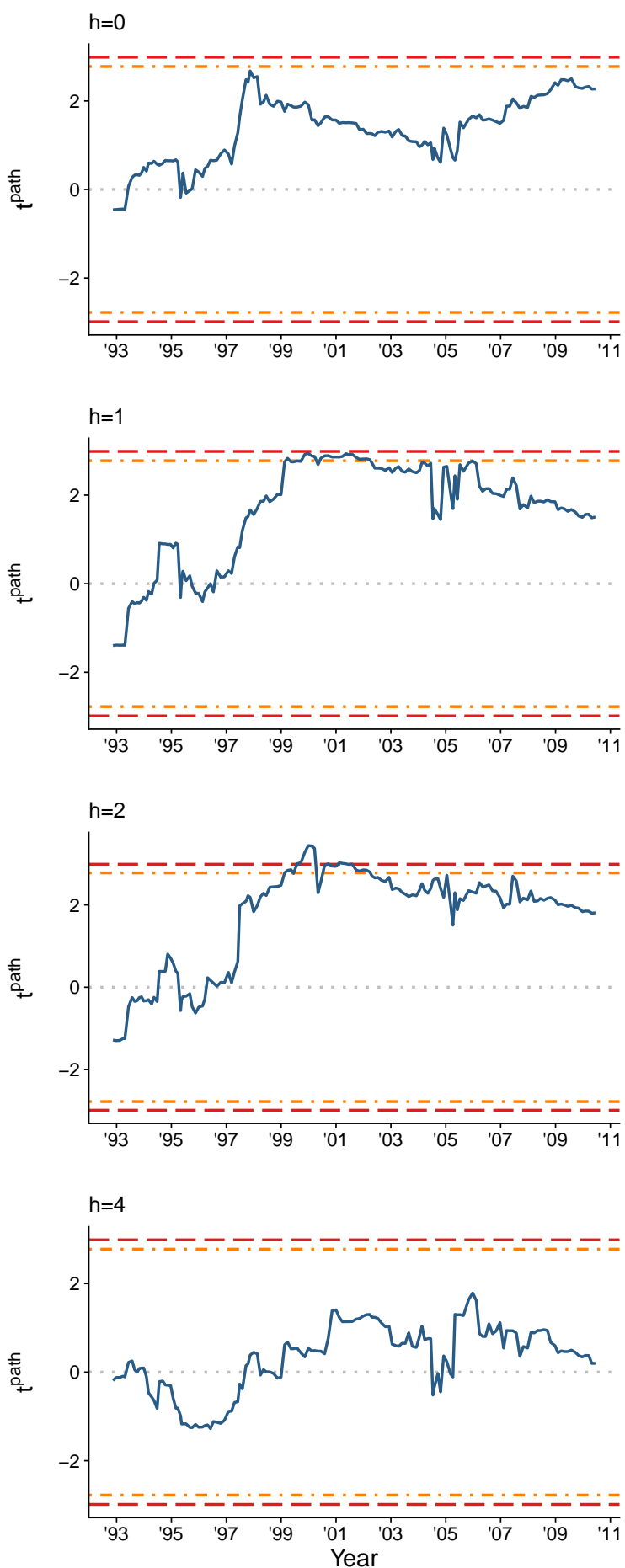

Notes. The figures show the path of the Fluctuation test statistics on the target factor (left panel) and path factor (right panel). The tests reject for test statistic values outside the $5 \%$ (red dashed lines) and $10 \%$ (orange dash-dotted line) critical value bands. 
Figure 14: Unemployment Rate: Forecast Response Fluctuation Test

A

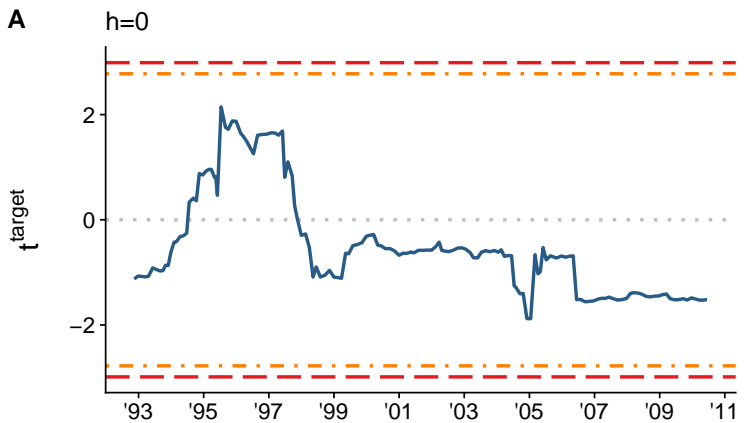

B
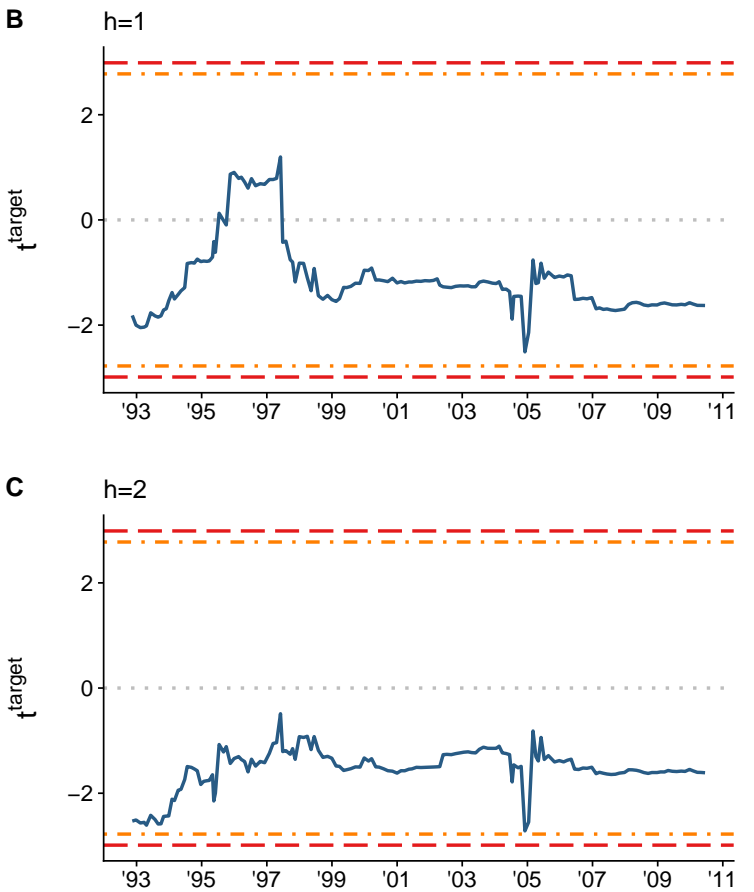

D $\quad \mathrm{h}=4$

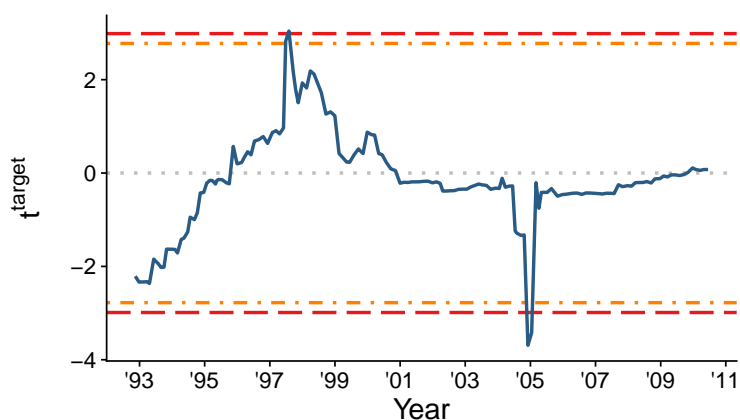

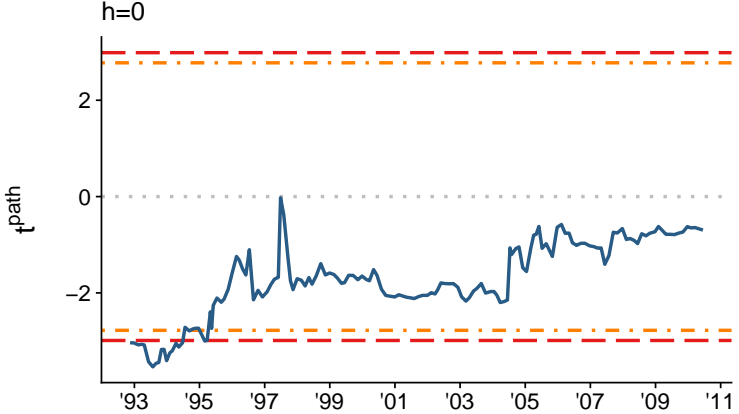
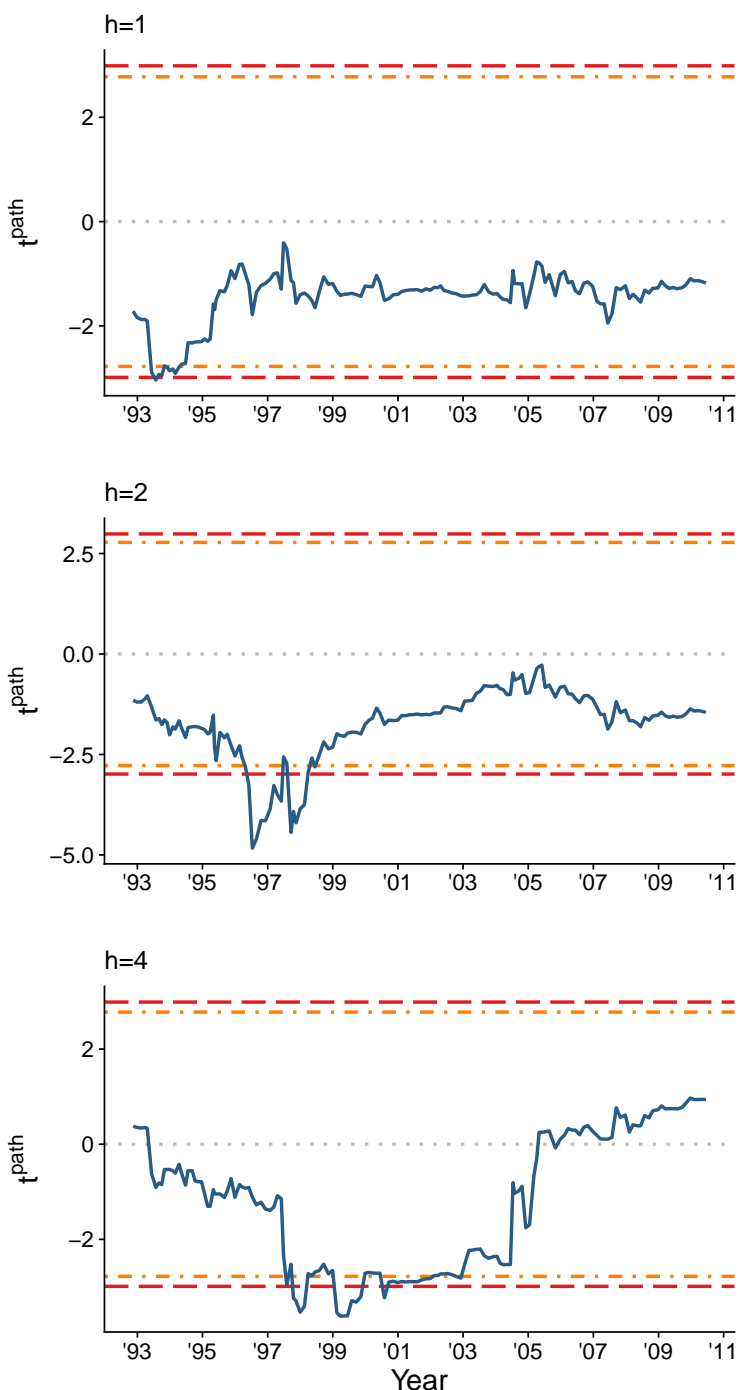

Notes. The figures show the path of the Fluctuation test statistics on the target factor (left panel) and path factor (right panel). The tests reject for test statistic values outside the 5\% (red dashed lines) and $10 \%$ (orange dash-dotted line) critical value bands. 
Figure 15: Interest Rate: Forecast Response Fluctuation Test
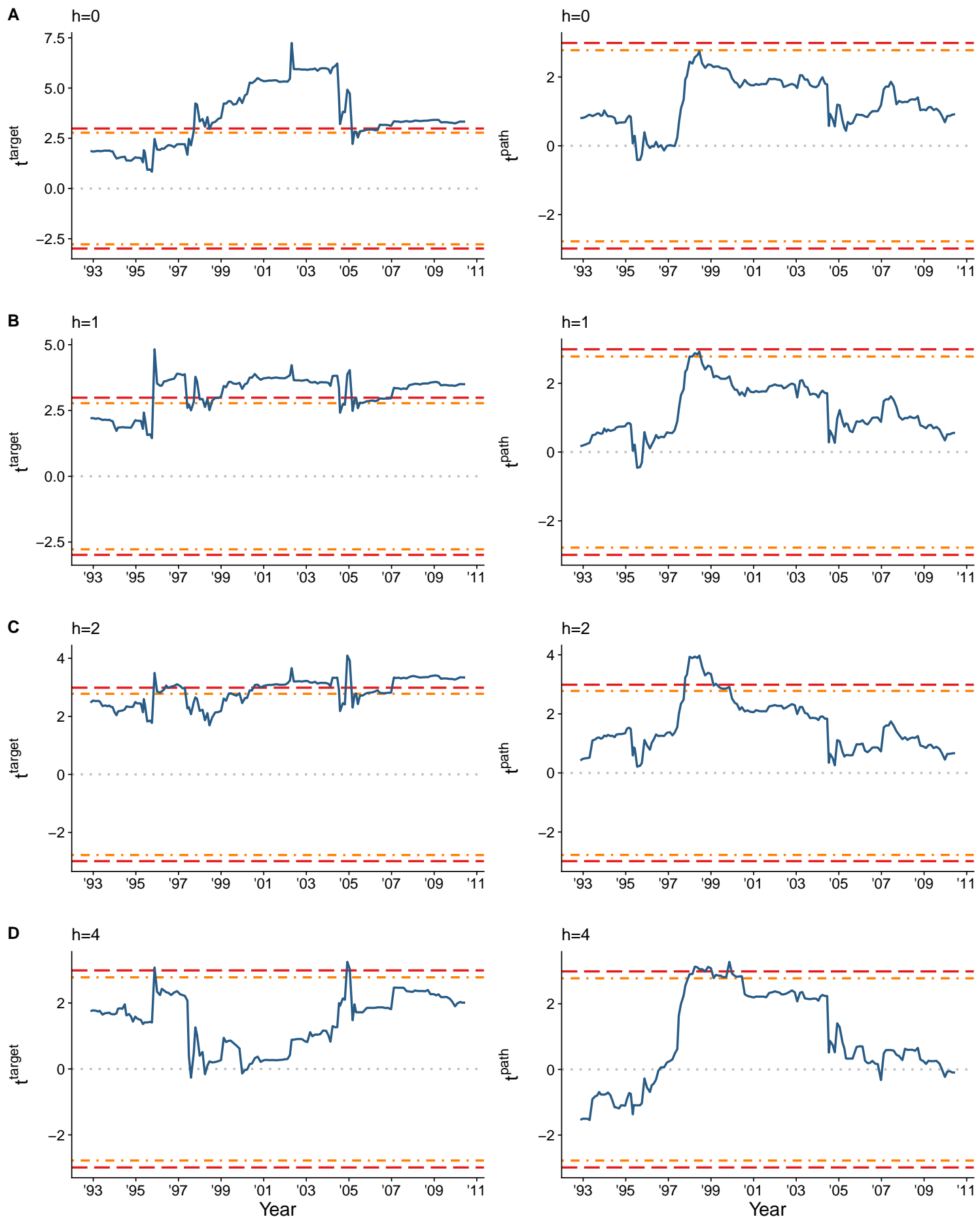

Notes. The figures show the path of the Fluctuation test statistics on the target factor (left panel) and path factor (right panel). The tests reject for test statistic values outside the $5 \%$ (red dashed lines) and $10 \%$ (orange dash-dotted line) critical value bands. 


\section{Conclusion}

This paper explores the empirical importance of the information channel of U.S. monetary policy and how it changed over time. We show that information-robust methods provide substantially different results when applied to the 1990s-early 2000s relative to the period afterwards, thus confirming the existence of an information channel of monetary policy early in the sample, which disappeared in mid-2000s. We document that such disappearance happens at the same time as the decrease in the information advantage of the central bank relative to private sector's forecasts. Our empirical results might be linked to several factors - including an improvement in the Fed's communication and transparency.

\section{References}

Andrade, P. And F. Ferroni (2018): "Delphic and odyssean monetary policy shocks: Evidence from the euro area," FRB of Chicago Working Paper No. WP-2018-12.

Bundick, B. AND A. L. Smith (2019): "The dynamic effects of forward guidance shocks," The Review of Economics and Statistics, Forthcoming.

Campbell, J. R., C. L. Evans, J. D. Fisher, A. Justiniano, C. W. Calomiris, AND M. WoOdFord (2012): "Macroeconomic effects of federal reserve forward guidance [with comments and discussion]," Brookings Papers on Economic Activity, 1-80.

Campbell, J. R., J. D. Fisher, A. Justiniano, And L. Melosi (2017): "Forward guidance and macroeconomic outcomes since the financial crisis," NBER Macroeconomics Annual, 31, 283-357.

Christiano, L. J., M. Eichenbaum, And C. L. Evans (1999): "Monetary policy shocks: What Have We Learned and to What End?" Handbook of Macroeconomics, 1, $65-148$.

(2005): "Nominal Rigidities and the Dynamic Effects of a Shock to Monetary Policy," Journal of Political Economy, 113, 1-45.

Croushore, D. (2012): "Comment-Forecast Rationality Tests Based on Multi-Horizon Bounds," Journal of Business and Economic Statistics, 30, 17-20.

D'Agostino, A., D. Giannone, and P. Surico (2006): "Federal Reserve Information During the Great Moderation," CEPR Discussion Papers, 6594.

D'Agostino, A. And K. Whelan (2008): "Federal Reserve Information During the Great Moderation," Journal of the European Economic Association, 6, 609-620. 
FAust, J. And J. H. Wright (2009): "Comparing Greenbook and reduced form forecasts using a large realtime dataset," Journal of Business 85 Economic Statistics, 27, $468-479$.

Gertler, M. And P. Karadi (2015): "Monetary policy surprises, credit costs, and economic activity," American Economic Journal: Macroeconomics, 7, 44-76.

Giacomini, R. And B. Rossi (2010): "Forecast Comparisons in Unstable Environments," Journal of Applied Econometrics, 25, 595-620.

GÜRKAynak, R. S., B. SACK, And E. Swanson (2005): "The sensitivity of long-term interest rates to economic news: Evidence and implications for macroeconomic models," American Economic Review, 95, 425-436.

Inoue, A. AND B. Rossi (2019): "The effects of conventional and unconventional monetary policy: A new approach," Mimeo.

JAROCINSKI, M. AND P. KARADI (2018): "Deconstructing monetary policy surprises: the role of information shocks," American Economic Journal: Macroeconomic (Forthcoming).

JoRDÀ, Ò. (2005): "Estimation and inference of impulse responses by local projections," American Economic Review, 95, 161-182.

Lunsford, K. G. (2018): "Understanding the Aspects of Federal Reserve Forward Guidance," mimeo.

Miranda-Agrippino, S. And G. Ricco (2018): "The transmission of monetary policy shocks," CEPR Discussion Paper No. DP13396.

NAKamura, E. And J. Steinsson (2018): "High-frequency identification of monetary non-neutrality: the information effect," The Quarterly Journal of Economics, 133, $1283-1330$.

Patton, A. J. And A. Timmermann (2012): "Forecast rationality tests based on multi-horizon bounds," Journal of Business 85 Economic Statistics, 30, 1-17.

Romer, C. D. And D. H. Romer (2000): "Federal Reserve information and the behavior of interest rates," American Economic Review, 90, 429-457.

(2004): "A new measure of monetary shocks: Derivation and implications," American Economic Review, 94, 1055-1084.

Rossi, B. AND T. SEKHPOSYAN (2016): "Forecast rationality tests in the presence of instabilities, with applications to Federal Reserve and survey forecasts," Journal of Applied Econometrics, 31, 507-532. 


\section{Appendix}

\section{A Additional Evidence on Information Channel}

This appendix provides additional empirical evidence on the presence of an information channel of monetary policy and its evolution over time. Whereas section 4 compared the impulse responses identified by the informationally robust shock by Miranda-Agrippino and Ricco (2018) to those obtained using Gertler and Karadi (2015), here we report comparisons with the extended narrative measure of Romer and Romer (2004).

Figure 16: Informationally Robust Analysis: Full Sample

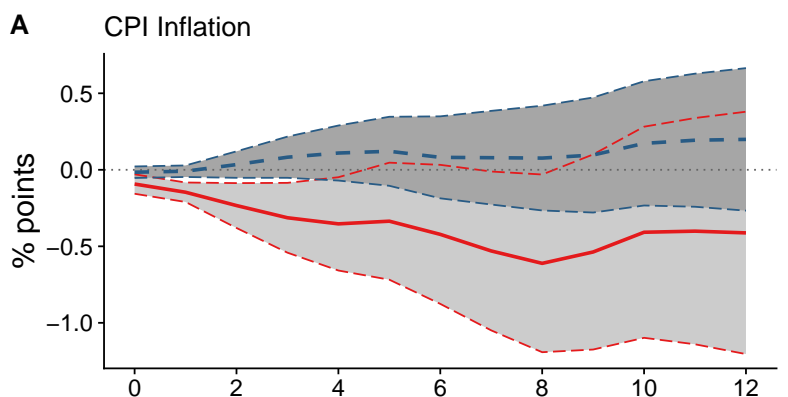

B Industrial Production

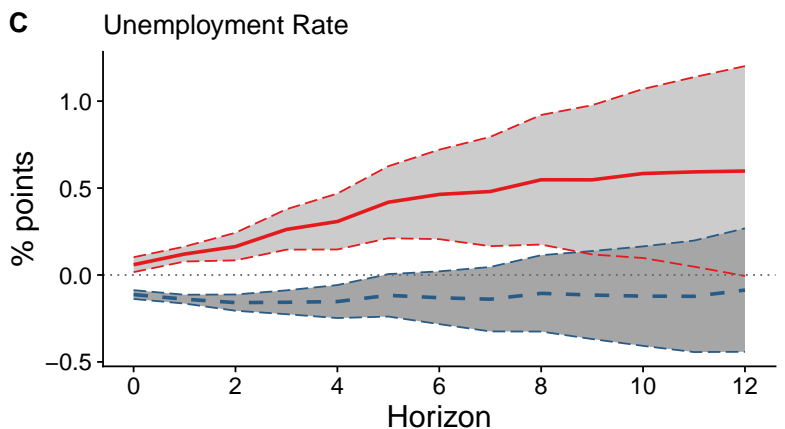

D

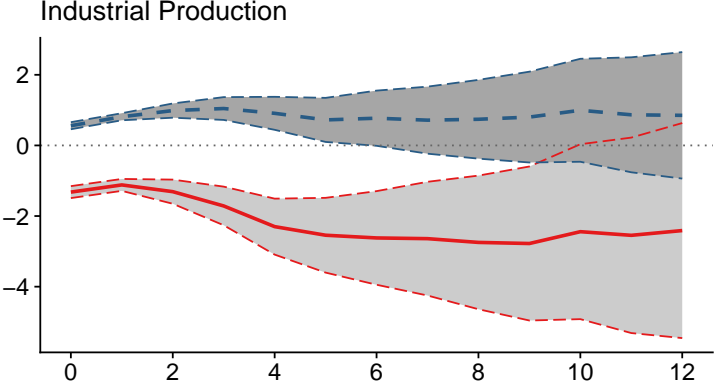

Instrument

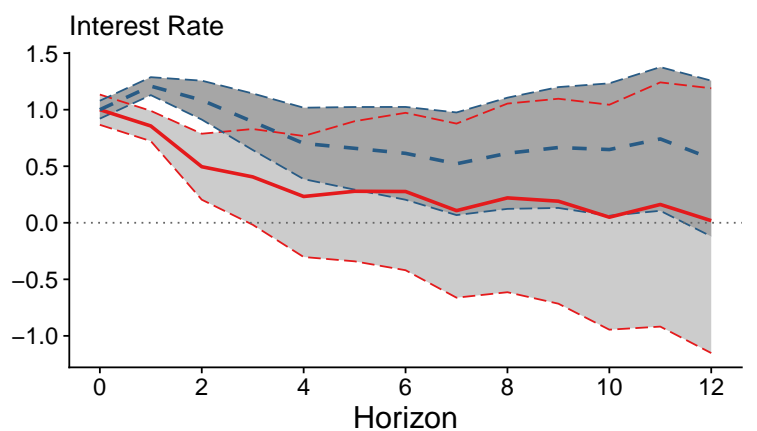

Miranda-Agrippino \& Ricco Romer \& Romer

Notes. Responses to monetary policy shocks under different identification assumptions: The blue dashed line denotes the shock identified with the extended narrative measure of Romer and Romer (2004) and the red solid line denotes the informationally robust shock by Miranda-Agrippino and Ricco (2018). The shock is normalized to induce a 100 basis point increase in the 1-year rate. The responses are estimated by local projections on the sample 1979:1 - 2014:12. Shaded areas are 90\% confidence bands based on robust standard errors. 
Figure 17: Informationally Robust Analysis: 1979-2003 and 2004-2014 subsamples
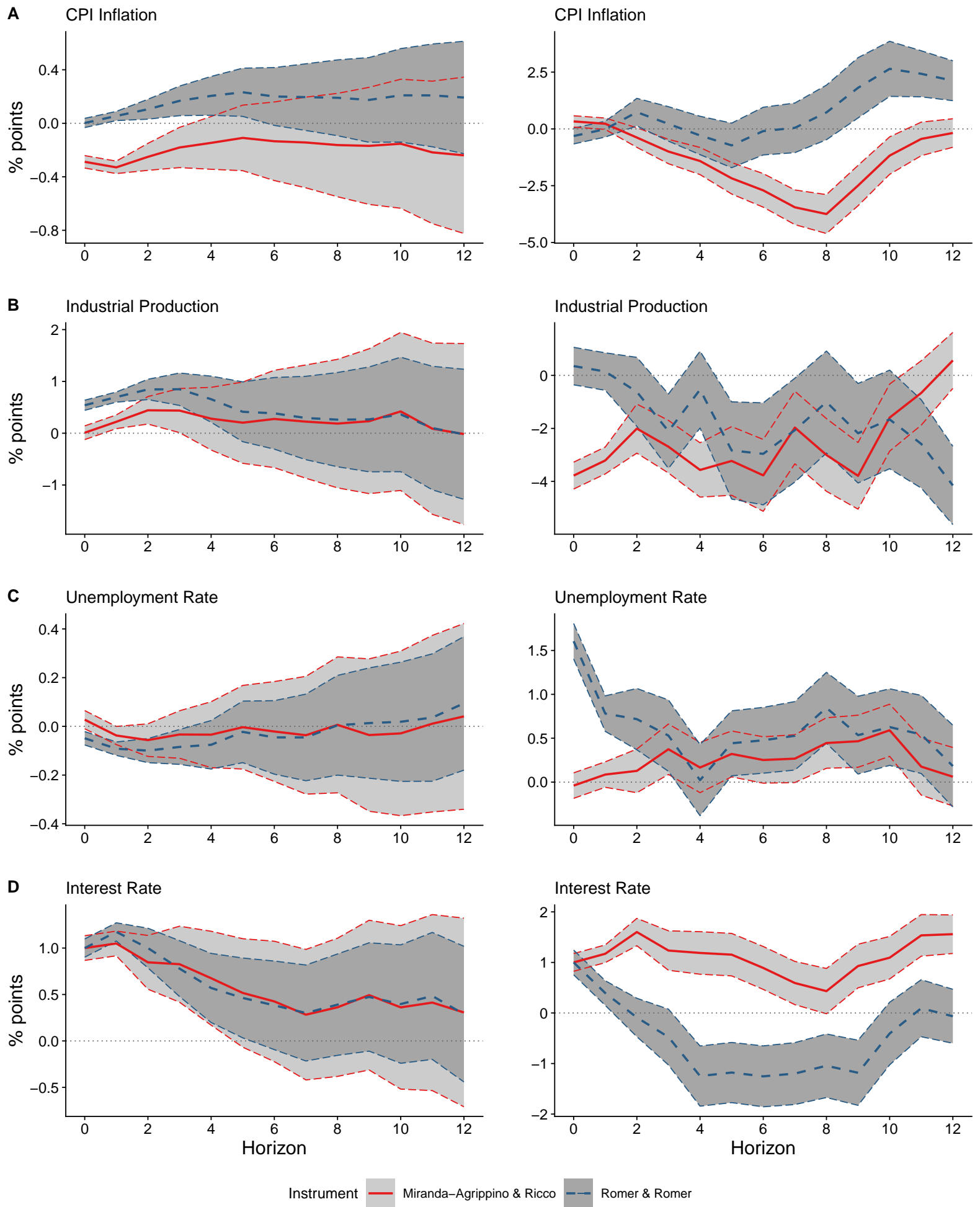

Notes. Responses to monetary policy shocks in two sub-samples: 1/1/1979-12/31/2003 (left panel) and 1/1/2004-31/12/2014 (right panel). The responses are obtained under different identification assumptions: The blue dashed line denotes the shock identified with the extended narrative measure of Romer and Romer (2004) and the red solid line denotes the informationally robust shock by Miranda-Agrippino and Ricco (2018). The shock is normalized to induce a 100 basis point increase in the 1-year rate. The responses are estimated by local projections. Shaded areas are $90 \%$ confidence bands based on robust standard errors. 


\section{B Information Advantage and Forecast Timing}

This section provides additional results on the robustness of the finding reported in Section 5 that the information advantage of the Federal Reserve forecasts is not present in the most recent data, either because it disappeared in the mid-2000s or because it was never there. Specifically, we address the concern that the result could be sensitive to the time-ordering of the publication dates of Greenbook/Tealbook and Blue-Chip Economic Indicator forecasts. Recall that, as discussed in Section 3, each monetary policy announcement date in our analysis corresponds to a Greenbook/Tealbook forecast and a Blue-Chip forecast. Inspecting these dates, which are listed in the table in Appendix A, we note that the Blue-Chip forecasts are always published on the 10th of each month, but the publication day of the Greenbook/Tealbook forecasts varies. One might be concerned that a systematic change in the ordering of forecasts over time resulting from variation in the publication date of the Greenbook/Tealbook forecasts might bias our findings about the informational advantage. For example, if Greenbook/Tealbook forecasts are systematically published after Blue-Chip forecasts during a specific period of time, those forecasts might outperform the Blue-Chip forecasts simply because there was news arriving between the publication of the forecasts or forecasters simply had more time to process available information.

To ensure that our finding of a disappearing information advantage is not driven by differences in the timing of the forecasts, we extend our analysis from Section 5 by running two robustness check regressions that we explain in detail below. However, first we conduct a descriptive analysis of the publication dates of Greenbook/Tealbook and Blue-Chip forecasts to get a sense for the timing differences occuring over our analysis sample.

Figure 18 illustrates the relative timing of the publication dates of Greenbook/Tealbook and Blue-Chip Economic Indicator forecasts. Panel 18.A addresses the concern that there is a systematic difference in forecast timings over the whole sample. The figure reports a histogram of the difference in days between the publication date of the Greenbook/Tealbook forecasts and the publication date of the Blue-Chip forecasts, associated with each FOMC announcement. Positive values imply that the Greenbook/Tealbook forecasts are published after the Blue-Chip forecasts, negative values imply the opposite ordering. The figure shows substantial variation in the relative publication dates. For the majority of forecasts, the Greenbook/Tealbook publication typically occurs with a lag of at least several days relative to the publication of the BCEI forecasts. This could imply that the forecasts of the Federal Reserve have substantially more time to process available information and can react to news arriving after the publication of the Blue-Chip forecasts. If this was the case, then the results from our tests conducted in Section 5 might be biased towards finding an information advantage for the Federal Reserve forecasts over the whole sample. However, our main result is that the information advantage has disappeared in 
Figure 18: Relative timing of Greenbook/Tealbook and BCEI Forecasts
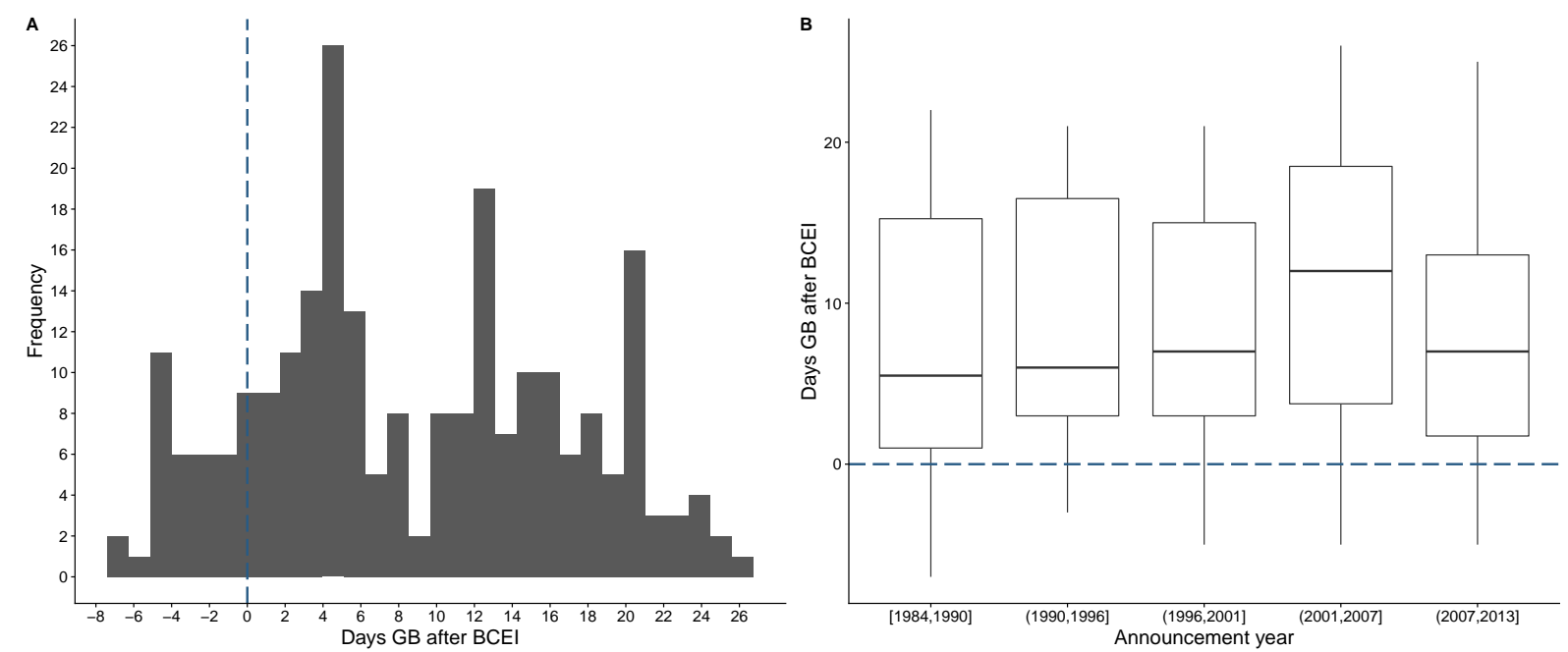

Notes. The figure illustrates the relative timing of the publication dates of Greenbook/Tealbook and Blue-Chip Economic Indicator Forecasts. Panel A shows the distribution of Greenbook/Tealbook publication dates relative to the publication date of the BCEI forecasts. Positive values imply that the Greenbook/Tealbook forecasts are published after the Blue-Chip forecasts. The Blue-Chip is published on the 10th of each month which corresponds to the vertical dashed line at zero. Panel B illustrates the change of this distribution over time by means of a boxplot.

recent years and thus removing such bias would simply further strengthen our finding. Panel 18.B addresses the concern that the relative timing discussed previously might be changing over time in a systematic way. The figure shows a series of boxplots which report the distribution of the publication lag of Greenbook/Tealbook forecasts relative to the Blue-Chip forecasts over five consecutive windows containing six years of data each. The figure indicates that the distriubtion of the lag of the Greenbook/Tealbook forecasts relative to the Blue-Chip forecasts has changed over time, with the mean lag slightly increasing between the beginning and end of the sample and being substantially higher in the 2002-2007 period. This could imply that our information advantage tests might be biased towards finding an information advantage for the Federal Reserve Forecasts in the later part of the sample rather than the earlier part of the sample. However, as we find the opposite of this, removing such potential bias would further strengthen our conclusion that there is no information advantage in recent years.

Finally, to address the concerns described above in a more formal way, we carry out two robustness checks for which we modify the regression studied in equation 5 . The first robustness check re-runs the the analysis we presented, but drops a set of FOMC meetings from the sample that might be particularly problematic with regard to the relative timing of Greenbook/Tealbook and Blue-Chip forecasts. Lunsford (2018) states that the Blue-Chip surveys are typically conducted within the first 2-3 working days of each month and therefore drops FOMC announcements occuring within this time period, Nakamura and Steinsson (2018) make a similar adjustment. This motivates our first 
robustness check in which we repeat our analysis from Section 5, dropping all FOMC announcements which occur within the first 3 working days of the month. The second robustness check extends the informational advantage regressions by including as a control variable an additional interaction term that captures the effect of the Greenbook/Tealbook forecasts being published before the Blue-Chip forecasts. Specifically, we run the following regression

$$
x_{t+h}-x_{t+h \mid t}^{B C E I}=\delta+\beta_{G B} x_{t+h \mid t}^{G B}+\beta_{B C E I} x_{t+h \mid t}^{B C I}+\gamma x_{t+h \mid t}^{G B} D_{G B \rightarrow B C E I}+\eta_{t+h}
$$

where $D_{G B \rightarrow B C E I}$ is a dummy variable that takes on value one if the publication date of the Greenbook/Tealbook associated with the announcement date comes strictly before the publication date of the Blue-Chip forecast. Again, Federal Reserve forecasts are useful beyond that of the private sector in predicting $x_{t+h}$ if and only if $\beta_{G B} \neq 0$ and we use the Fluctuation tests to test this hypothesis robust to instabilities in $\beta_{G B}$.

Figures 19-22 report the Information-Advantage Fluctuation test statistics $t_{G B}$ from the robustness check regressions and compare them to our original findings from Section 5. The solid blue line denotes the original Fluctuation test statistic $t_{G B}$ reported in Section 5. The dotted purple line indicates the Fluctuation test statistic that is obtained when dropping FOMC meetings in the first 3 business days as described above. The orange dashed line reports the Fluctuation test statistic from the information advantage regression with the timing dummy in equation (5).

The figures clearly show that our main findings remain robust to carrying out the analysis taking the relative timing of the Greenbook/Tealbook and the Blue-Chip forecasts into account. Specifically, the Fluctuation test statistics from regression (5) with the timing dummy are very close to the original test statistics. For the robustness check that drops FOMC meetings occurring in the first three business days of the corresponding months, the test statistic values show larger changes, but our main conclusions remain valid across variables and horizons. Only for one-quarter-ahead inflation forecasts and forecasts of the interest rate at $h=1,2$ does the path of the test statistic of the robustness check indicate that the information advantage disappeared slightly earlier in the sample as indicated by the original test statistic. 
Figure 19: Inflation: Information-Advantage Test and Forecast Timing
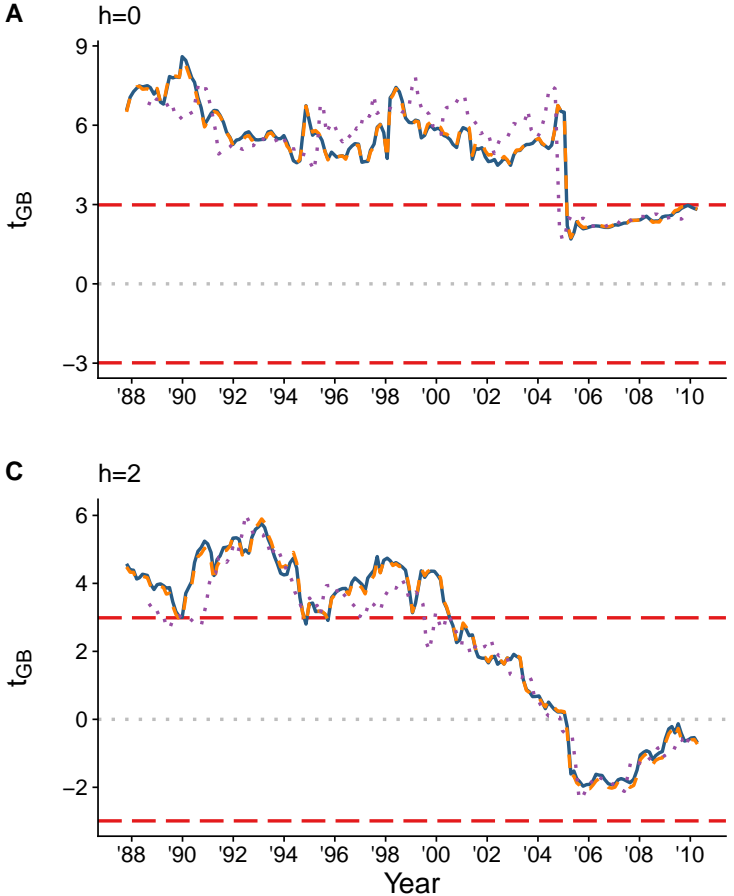

B

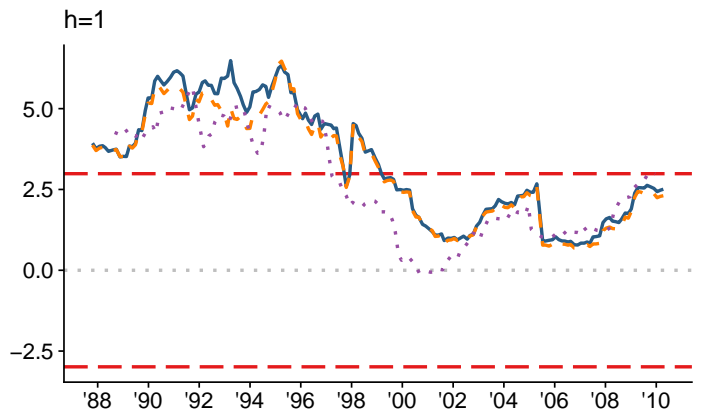

D

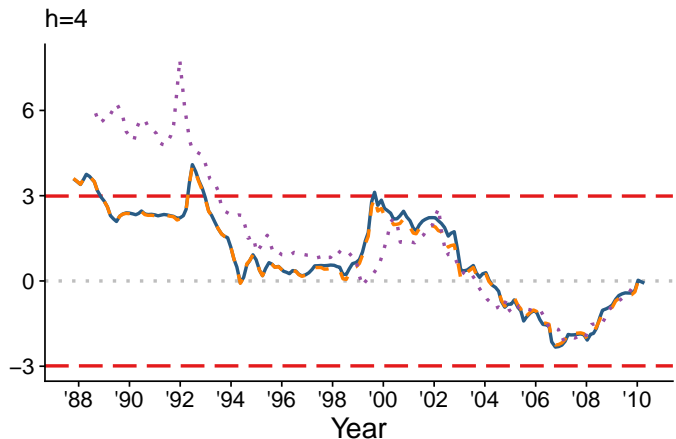

Notes. The figure reports the original Fluctuation test statistic $t_{G B}$ (blue solid line) together with the Fluctuation test statistic obtained when dropping FOMC meetings in the first 3 business days (dotted purple line) and when including a timing dummy as an additional control (orange dashed line).

Figure 20: GDP Growth: Information-Advantage Test and Forecast Timing
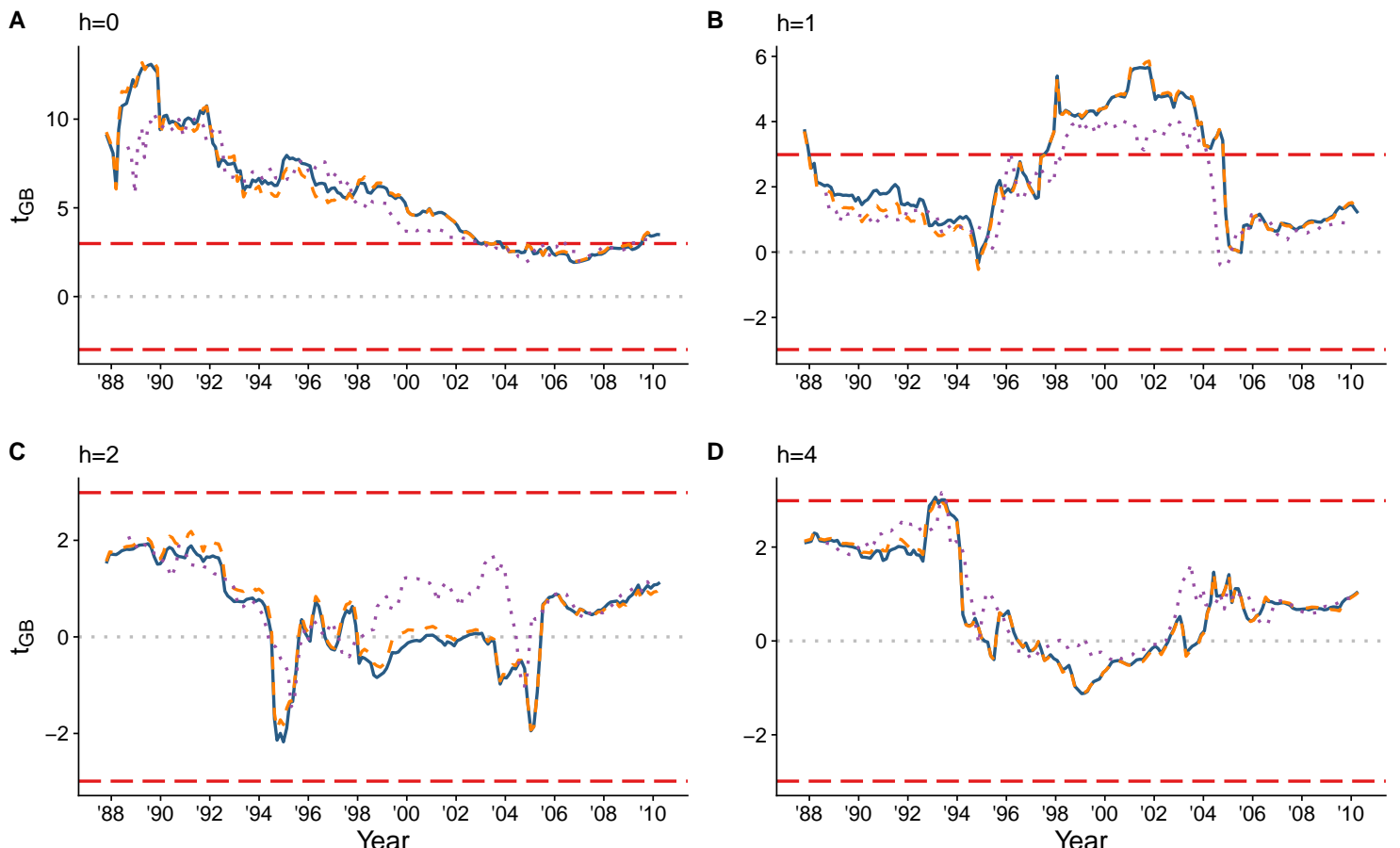

Notes. The figure reports the original Fluctuation test statistic $t_{G B}$ (blue solid line) together with the Fluctuation test statistic obtained when dropping FOMC meetings in the first 3 business days (dotted purple line) and when including a timing dummy as an additional control (orange dashed line). 
Figure 21: Unemployment Rate: Information-Advantage Test and Forecast Timing
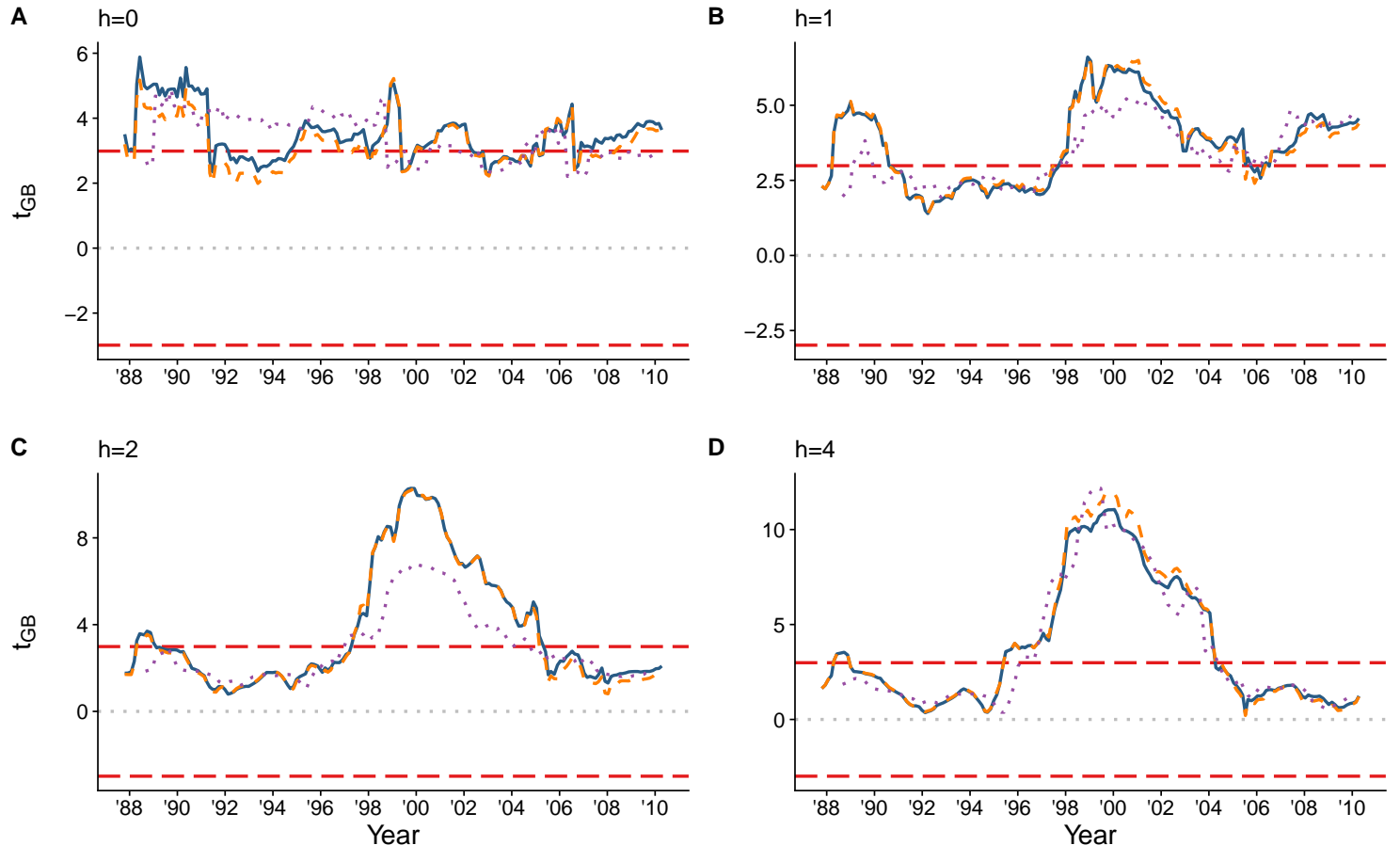

Notes. The figure reports the original Fluctuation test statistic $t_{G B}$ (blue solid line) together with the Fluctuation test statistic obtained when dropping FOMC meetings in the first 3 business days (dotted purple line) and when including a timing dummy as an additional control (orange dashed line).

Figure 22: Interest Rate: Information-Advantage Test and Forecast Timing

A
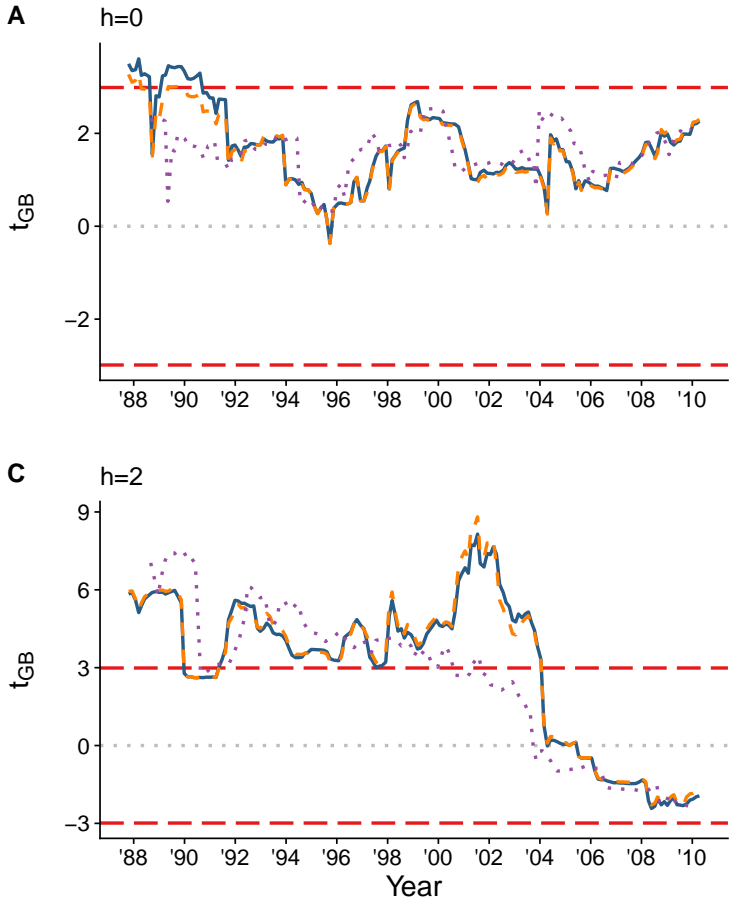

B $\quad \mathrm{h}=1$

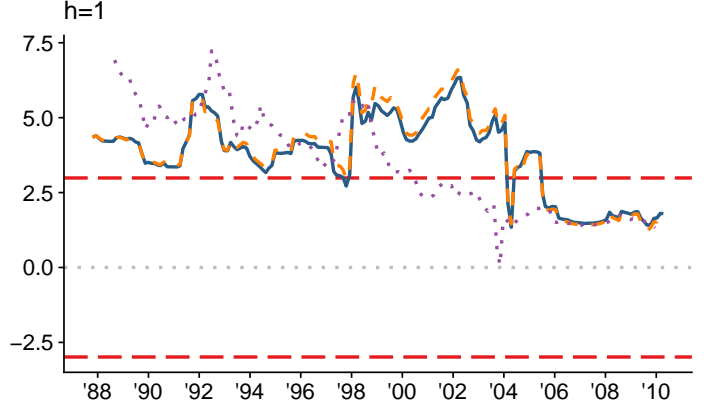

D

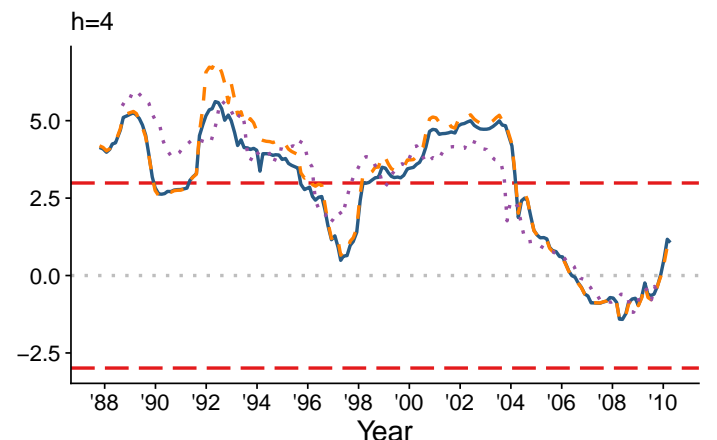

Notes. The figure reports the original Fluctuation test statistic $t_{G B}$ (blue solid line) together with the Fluctuation test statistic obtained when dropping FOMC meetings in the first 3 business days (dotted purple line) and when including a timing dummy as an additional control (orange dashed line). 


\section{Appendix - Not for publication}

\section{A Monetary Policy Announcements}

The following table reports the dates of the FOMC announcements used in the analysis as well as the corresponding publication dates of Greenbook/Tealbook and BCEI forecasts. The columns report in the following order: the date of the FOMC announcement, the publication date of the associated Greenbook/Tealbook forecasts, the publication date of the matched BCEI forecast and the BCEI dates used to compute the revisions in the forecast.

Table 2: FOMC announcements used in the Analyses

\begin{tabular}{|c|c|c|c|c|}
\hline Announcement & Greenbook/Tealbook & BCEI & Previous BCEI & Next BCEI \\
\hline 01 Feb '84 & 25 Jan '84 & 10 Jan '84 & 10 Jan '84 & 10 Feb '84 \\
\hline 28 Mar '84 & 21 Mar' 84 & 10 Mar '84 & 10 Mar '84 & 10 Apr '84 \\
\hline 23 May '84 & 16 May '84 & 10 May '84 & 10 May '84 & 10 Jun '84 \\
\hline 18 Jul '84 & 11 Jul '84 & $10 \mathrm{Jul}$ '84 & 10 Jul '84 & 10 Aug '84 \\
\hline 22 Aug '84 & 15 Aug '84 & 10 Aug '84 & 10 Aug '84 & 10 Sep '84 \\
\hline 03 Oct ' 84 & 26 Sep '84 & 10 Sep '84 & 10 Sep '84 & 10 Oct ' 84 \\
\hline 08 Nov '84 & 31 Oct '84 & 10 Oct ' 84 & 10 Oct ' 84 & 10 Nov '84 \\
\hline 21 Nov' 84 & & 10 Nov' 84 & 10 Nov' 84 & 10 Dec ' 84 \\
\hline 19 Dec '84 & 12 Dec '84 & 10 Dec ' 84 & 10 Dec '84 & 10 Jan '85 \\
\hline 21 Dec '84 & & 10 Dec '84 & 10 Dec '84 & 10 Jan '85 \\
\hline 14 Feb '85 & 06 Feb '85 & 10 Feb '85 & 10 Feb '85 & 10 Mar' 85 \\
\hline 21 Feb '85 & & 10 Feb ' 85 & 10 Feb '85 & 10 Mar' 85 \\
\hline 27 Mar '85 & 20 Mar '85 & 10 Mar '85 & 10 Mar '85 & 10 Apr '85 \\
\hline 18 Apr '85 & & 10 Apr '85 & 10 Apr '85 & 10 May ' 85 \\
\hline 17 May '85 & & 10 May '85 & 10 May '85 & 10 Jun '85 \\
\hline 22 May '85 & 15 May '85 & 10 May '85 & 10 May '85 & 10 Jun '85 \\
\hline 11 Jul '85 & 03 Jul '85 & $10 \mathrm{Jul}$ '85 & 10 Jul '85 & 10 Aug '85 \\
\hline 01 Aug '85 & & $10 \mathrm{Jul}$ '85 & $10 \mathrm{Jul}$ '85 & 10 Aug '85 \\
\hline 21 Aug '85 & 14 Aug '85 & 10 Aug '85 & 10 Aug '85 & 10 Sep '85 \\
\hline 06 Sep '85 & & 10 Aug '85 & 10 Aug '85 & 10 Sep '85 \\
\hline 02 Oct ' 85 & 25 Sep '85 & 10 Sep '85 & 10 Sep '85 & 10 Oct ' 85 \\
\hline 06 Nov' 85 & 30 Oct ' 85 & 10 Oct '85 & 10 Oct ' 85 & 10 Nov '85 \\
\hline 18 Dec '85 & 11 Dec '85 & 10 Dec '85 & 10 Dec '85 & 10 Jan '86 \\
\hline 13 Feb '86 & 05 Feb '86 & 10 Feb '86 & 10 Feb '86 & 10 Mar' 86 \\
\hline 07 Mar '86 & & 10 Feb '86 & 10 Feb '86 & 10 Mar '86 \\
\hline 02 Apr '86 & 26 Mar '86 & 10 Mar '86 & 10 Mar '86 & 10 Apr '86 \\
\hline 18 Apr '86 & & 10 Apr '86 & 10 Apr '86 & 10 May '86 \\
\hline 21 May '86 & 14 May '86 & 10 May '86 & 10 May '86 & 10 Jun '86 \\
\hline 05 Jun '86 & & 10 May '86 & 10 May '86 & 10 Jun '86 \\
\hline $10 \mathrm{Jul}$ '86 & $02 \mathrm{Jul}$ '86 & 10 Jun '86 & 10 Jun '86 & $10 \mathrm{Jul}$ '86 \\
\hline 14 Aug '86 & & 10 Aug '86 & 10 Aug '86 & 10 Sep '86 \\
\hline 20 Aug '86 & 13 Aug '86 & 10 Aug '86 & 10 Aug '86 & 10 Sep '86 \\
\hline
\end{tabular}




\begin{tabular}{|c|c|c|c|c|}
\hline 24 Sep '86 & 17 Sep '86 & 10 Sep '86 & 10 Sep '86 & 10 Oct ' 86 \\
\hline 06 Nov '86 & 29 Oct ' 86 & 10 Oct ' 86 & 10 Oct ' 86 & 10 Nov ' 86 \\
\hline 17 Dec '86 & 10 Dec '86 & 10 Dec '86 & 10 Dec '86 & 10 Jan '87 \\
\hline 15 Jan '87 & & 10 Jan '87 & 10 Jan '87 & 10 Feb '87 \\
\hline 12 Feb '87 & 04 Feb '87 & 10 Feb '87 & 10 Feb '87 & 10 Mar '87 \\
\hline 01 Apr '87 & 25 Mar '87 & 10 Mar '87 & 10 Mar '87 & 10 Apr '87 \\
\hline 30 Apr '87 & & 10 Apr '87 & 10 Apr '87 & 10 May ' 87 \\
\hline 20 May '87 & 13 May '87 & 10 May '87 & 10 May '87 & 10 Jun ' 87 \\
\hline 08 Jul '87 & $01 \mathrm{Jul}$ '87 & 10 Jun '87 & 10 Jun '87 & 10 Jul ' 87 \\
\hline 19 Aug '87 & 12 Aug '87 & 10 Aug '87 & 10 Aug '87 & 10 Sep '87 \\
\hline 03 Sep '87 & & 10 Aug '87 & 10 Aug '87 & 10 Sep '87 \\
\hline 04 Sep '87 & & 10 Aug '87 & 10 Aug '87 & 10 Sep '87 \\
\hline 23 Sep '87 & 16 Sep '87 & 10 Sep '87 & 10 Sep '87 & 10 Oct ' 87 \\
\hline 23 Oct '87 & & 10 Oct ' 87 & 10 Oct ' 87 & 10 Nov' 87 \\
\hline 28 Oct ' 87 & & 10 Oct ' 87 & 10 Oct '87 & 10 Nov ' 87 \\
\hline 04 Nov '87 & 28 Oct ' 87 & 10 Oct ' 87 & 10 Oct ' 87 & 10 Nov ' 87 \\
\hline 17 Dec '87 & 09 Dec '87 & 10 Dec '87 & 10 Dec '87 & 10 Jan '88 \\
\hline 28 Jan '88 & & 10 Jan '88 & 10 Jan '88 & 10 Feb '88 \\
\hline 11 Feb '88 & 03 Feb '88 & 10 Feb '88 & 10 Feb '88 & 10 Mar '8 \\
\hline 30 Mar '88 & 23 Mar '88 & 10 Mar '88 & 10 Mar '88 & 10 Apr '8 \\
\hline 09 May '88 & & 10 Apr '88 & 10 Apr '88 & 10 May '\& \\
\hline 18 May '88 & 11 May '88 & 10 May '88 & 10 May '88 & 10 Jun '8 \\
\hline 25 May '88 & & 10 May '88 & 10 May '88 & 10 Jun '88 \\
\hline 22 Jun '88 & & 10 Jun '88 & 10 Jun '88 & $10 \mathrm{Jul}$ ' 88 \\
\hline $01 \mathrm{Jul}$ '88 & 22 Jun '88 & 10 Jun '88 & 10 Jun '88 & $10 \mathrm{Jul}$ ' 88 \\
\hline $19 \mathrm{Jul}$ '88 & & 10 Jul '88 & $10 \mathrm{Jul}$ '88 & 10 Aug '8 \\
\hline 09 Aug '88 & & $10 \mathrm{Jul}$ '88 & $10 \mathrm{Jul}$ ' 88 & 10 Aug '8 \\
\hline 17 Aug '88 & 10 Aug '88 & 10 Aug '88 & 10 Aug '88 & 10 Sep ' 8 \\
\hline 21 Sep '88 & 14 Sep '88 & 10 Sep '88 & 10 Sep '88 & 10 Oct ' 8 \\
\hline 02 Nov '88 & 26 Oct ' 88 & 10 Oct ' 88 & 10 Oct ' 88 & 10 Nov '88 \\
\hline 10 Nov '88 & & 10 Oct ' 88 & 10 Oct ' 88 & 10 Nov' 8 \\
\hline 22 Nov '88 & & 10 Nov '88 & 10 Nov '88 & 10 Dec ' 88 \\
\hline 15 Dec '88 & 07 Dec '88 & 10 Dec '88 & 10 Dec '88 & 10 Jan '89 \\
\hline 05 Jan '89 & & 10 Dec '88 & 10 Dec '88 & 10 Jan '89 \\
\hline 09 Feb '89 & 01 Feb '89 & 10 Jan '89 & 10 Jan '89 & 10 Feb '89 \\
\hline 14 Feb '89 & & 10 Feb '89 & 10 Feb '89 & 10 Mar '89 \\
\hline 24 Feb '89 & & 10 Feb '89 & 10 Feb '89 & 10 Mar '89 \\
\hline 29 Mar '89 & 22 Mar '89 & 10 Mar '89 & 10 Mar '89 & 10 Apr '89 \\
\hline 17 May '89 & 10 May '89 & 10 May '89 & 10 May '89 & 10 Jun '89 \\
\hline 06 Jun '89 & & 10 May '89 & 10 May '89 & 10 Jun '89 \\
\hline 07 Jul '89 & 28 Jun '89 & 10 Jun '89 & 10 Jun '89 & 10 Jul '89 \\
\hline 26 Jul '89 & & 10 Jul '89 & 10 Jul '89 & 10 Aug '89 \\
\hline 23 Aug '89 & 16 Aug '89 & 10 Aug '89 & 10 Aug '89 & 10 Sep '8 \\
\hline 04 Oct '89 & 27 Sep '89 & 10 Sep '89 & 10 Sep '89 & 10 Oct ' 8 \\
\hline 16 Oct '89 & & 10 Oct ' 89 & 10 Oct ' 89 & 10 Nov '89 \\
\hline 07 Nov '89 & & 10 Oct ' 89 & 10 Oct ' 89 & 10 Nov '8 \\
\hline 15 Nov '89 & 08 Nov '89 & 10 Nov '89 & 10 Nov '89 & 10 Dec '89 \\
\hline 20 Dec '89 & 13 Dec '89 & 10 Dec '89 & 10 Dec '89 & 10 Jan '9 \\
\hline
\end{tabular}




\begin{tabular}{|c|c|c|c|c|}
\hline 08 Feb '90 & 31 Jan '90 & 10 Jan '90 & 10 Jan '90 & 10 Feb '90 \\
\hline 28 Mar '90 & 21 Mar '90 & 10 Mar '90 & 10 Mar '90 & 10 Apr '90 \\
\hline 16 May '90 & 09 May '90 & 10 May '90 & 10 May '90 & 10 Jun '90 \\
\hline 05 Jul '90 & 27 Jun '90 & 10 Jun '90 & 10 Jun '90 & $10 \mathrm{Jul}$ '90 \\
\hline 13 Jul '90 & & 10 Jul '90 & 10 Jul '90 & 10 Aug '90 \\
\hline 22 Aug '90 & 15 Aug '90 & 10 Aug '90 & 10 Aug '90 & 10 Sep '90 \\
\hline 03 Oct '90 & 26 Sep '90 & 10 Sep '90 & 10 Sep '90 & 10 Oct '90 \\
\hline 29 Oct '90 & & 10 Oct '90 & 10 Oct '90 & 10 Nov '9 \\
\hline 14 Nov '90 & 07 Nov '90 & 10 Nov '90 & 10 Nov '90 & 10 Dec '90 \\
\hline 07 Dec '90 & & 10 Nov '90 & 10 Nov '90 & 10 Dec '90 \\
\hline 18 Dec '90 & 12 Dec '90 & 10 Dec '90 & 10 Dec '90 & 10 Jan '91 \\
\hline 08 Jan '91 & & 10 Dec '90 & 10 Dec '90 & 10 Jan '91 \\
\hline 01 Feb '91 & & 10 Jan '91 & 10 Jan '91 & 10 Feb '91 \\
\hline 07 Feb '91 & 30 Jan '91 & 10 Jan '91 & 10 Jan '91 & 10 Feb '91 \\
\hline 08 Mar '91 & & 10 Feb '91 & 10 Feb '91 & 10 Mar '9 \\
\hline 27 Mar '91 & 20 Mar '91 & 10 Mar '91 & 10 Mar '91 & 10 Apr '9 \\
\hline 30 Apr '91 & & 10 Apr '91 & 10 Apr '91 & 10 May '9 \\
\hline 15 May '91 & 08 May '91 & 10 May '91 & 10 May '91 & 10 Jun '91 \\
\hline 05 Jul '91 & 28 Jun '91 & 10 Jun '91 & 10 Jun '91 & 10 Jul '91 \\
\hline 06 Aug '91 & & 10 Jul '91 & 10 Jul '91 & 10 Aug '9 \\
\hline 21 Aug '91 & 14 Aug '91 & 10 Aug '91 & 10 Aug '91 & 10 Sep '91 \\
\hline 13 Sep '91 & & 10 Sep '91 & 10 Sep '91 & 10 Oct '9 \\
\hline 02 Oct '91 & 25 Sep '91 & 10 Sep '91 & 10 Sep '91 & 10 Oct '91 \\
\hline 30 Oct '91 & & 10 Oct '91 & 10 Oct '91 & 10 Nov '91 \\
\hline 06 Nov '91 & 30 Oct '91 & 10 Oct '91 & 10 Oct '91 & 10 Nov '91 \\
\hline 06 Dec '91 & & 10 Nov '91 & 10 Nov '91 & 10 Dec '91 \\
\hline 18 Dec '91 & 11 Dec '91 & 10 Dec '91 & 10 Dec '91 & 10 Jan '92 \\
\hline 20 Dec '91 & & 10 Dec '91 & 10 Dec '91 & 10 Jan '92 \\
\hline 06 Feb '92 & 30 Jan '92 & 10 Jan '92 & 10 Jan '92 & 10 Feb '92 \\
\hline 01 Apr '92 & & 10 Mar '92 & 10 Mar '92 & 10 Apr '9 \\
\hline 09 Apr '92 & & 10 Mar '92 & 10 Mar '92 & 10 Apr '9 \\
\hline 20 May '92 & 14 May '92 & 10 May '92 & 10 May '92 & 10 Jun '92 \\
\hline 02 Jul '92 & 26 Jun '92 & 10 Jun '92 & 10 Jun '92 & 10 Jul '92 \\
\hline 19 Aug '92 & 13 Aug '92 & 10 Aug '92 & 10 Aug '92 & 10 Sep '92 \\
\hline 04 Sep '92 & & 10 Aug '92 & 10 Aug '92 & 10 Sep '92 \\
\hline 07 Oct '92 & 30 Sep '92 & 10 Sep '92 & 10 Sep '92 & 10 Oct ' 9 \\
\hline 18 Nov '92 & 12 Nov' '92 & 10 Nov' 92 & 10 Nov'92 & 10 Dec '9 \\
\hline 23 Dec '92 & 16 Dec '92 & 10 Dec '92 & 10 Dec '92 & 10 Jan '93 \\
\hline 04 Feb '93 & 29 Jan '93 & 10 Jan '93 & 10 Jan '93 & 10 Feb '9 \\
\hline 24 Mar '93 & 17 Mar '93 & 10 Mar '93 & 10 Mar '93 & 10 Apr '9 \\
\hline 19 May '93 & 14 May '93 & 10 May '93 & 10 May '93 & 10 Jun '93 \\
\hline 08 Jul '93 & 30 Jun '93 & 10 Jun '93 & 10 Jun '93 & 10 Jul '93 \\
\hline 18 Aug '93 & 11 Aug '93 & 10 Aug '93 & 10 Aug '93 & 10 Sep '93 \\
\hline 22 Sep '93 & 15 Sep '93 & 10 Sep '93 & 10 Sep '93 & 10 Oct '93 \\
\hline 17 Nov '93 & 10 Nov '93 & 10 Nov '93 & 10 Nov'93 & 10 Dec '93 \\
\hline 22 Dec '93 & 15 Dec '93 & 10 Dec '93 & 10 Dec '93 & 10 Jan '94 \\
\hline 04 Feb '94 & 31 Jan '94 & 10 Jan '94 & 10 Jan '94 & 10 Feb '9 \\
\hline 22 Mar '94 & 16 Mar '94 & 10 Mar '94 & 10 Mar '94 & 10 Apr '9 \\
\hline
\end{tabular}


18 Apr '94

17 May '94

06 Jul '94

16 Aug '94

27 Sep '94

15 Nov' '94

20 Dec '94

01 Feb '95

28 Mar '95

23 May '95

06 Jul '95

22 Aug '95

26 Sep '95

15 Nov' '95

19 Dec '95

31 Jan '96

26 Mar '96

21 May '96

03 Jul '96

20 Aug '96

24 Sep '96

13 Nov'96

17 Dec '96

05 Feb '97

25 Mar '97

20 May '97

02 Jul '97

19 Aug '97

30 Sep '97

12 Nov '97

16 Dec '97

04 Feb '98

31 Mar '98

19 May '98

$01 \mathrm{Jul}$ '98

18 Aug '98

29 Sep '98

15 Oct '98

17 Nov' '98

22 Dec '98

03 Feb '99

30 Mar '99

18 May '99

30 Jun '99

24 Aug '99

05 Oct '99

16 Nov '99

21 Dec '99
13 May '94

30 Jun '94

12 Aug '94

21 Sep '94

09 Nov '94

14 Dec '94

25 Jan '95

22 Mar '95

17 May '95

28 Jun '95

16 Aug '95

20 Sep '95

08 Nov '95

14 Dec '95

26 Jan '96

21 Mar'96

16 May '96

26 Jun '96

15 Aug '96

18 Sep '96

06 Nov '96

12 Dec '96

29 Jan '97

19 Mar '97

15 May '97

25 Jun '97

14 Aug '97

24 Sep '97

06 Nov '97

11 Dec '97

28 Jan '98

25 Mar' 98

14 May '98

24 Jun '98

13 Aug '98

23 Sep '98

12 Nov '98

16 Dec '98

28 Jan '99

24 Mar '99

13 May '99

23 Jun '99

18 Aug '99

29 Sep '99

10 Nov '99

15 Dec '99
10 Apr '94

10 May '94

10 Jun '94

10 Aug '94

10 Sep '94

10 Nov'94

10 Dec '94

10 Jan '95

10 Mar '95

10 May '95

10 Jun '95

10 Aug '95

10 Sep '95

10 Nov'95

10 Dec '95

10 Jan '96

10 Mar '96

10 May '96

10 Jun '96

10 Aug '96

10 Sep '96

10 Nov '96

10 Dec '96

10 Jan '97

10 Mar '97

10 May '97

10 Jun '97

10 Aug '97

10 Sep '97

10 Nov' 97

10 Dec '97

10 Jan '98

10 Mar '98

10 May '98

10 Jun '98

10 Aug '98

10 Sep '98

10 Oct '98

10 Nov' '98

10 Dec '98

10 Jan '99

10 Mar '99

10 May '99

10 Jun '99

10 Aug '99

10 Sep '99

10 Nov'99

10 Dec '99
10 Apr '94

10 May '94

10 Jun '94

10 Aug '94

10 Sep '94

10 Nov'94

10 Dec '94

10 Jan '95

10 Mar '95

10 May '95

10 Jun '95

10 Aug '95

10 Sep '95

10 Nov'95

10 Dec '95

10 Jan '96

10 Mar '96

10 May '96

10 Jun '96

10 Aug '96

10 Sep '96

10 Nov' '96

10 Dec '96

10 Jan '97

10 Mar '97

10 May '97

10 Jun '97

10 Aug '97

10 Sep '97

10 Nov' 97

10 Dec '97

10 Jan '98

10 Mar '98

10 May '98

10 Jun '98

10 Aug '98

10 Sep '98

10 Oct '98

10 Nov' 98

10 Dec '98

10 Jan '99

10 Mar '99

10 May '99

10 Jun '99

10 Aug '99

10 Sep '99

10 Nov' '99

10 Dec '99
10 May '94

10 Jun '94

10 Jul '94

10 Sep '94

10 Oct '94

10 Dec '94

10 Jan '95

10 Feb '95

10 Apr '95

10 Jun '95

10 Jul '95

10 Sep '95

10 Oct '95

10 Dec '95

10 Jan '96

10 Feb '96

10 Apr '96

10 Jun '96

$10 \mathrm{Jul}$ '96

10 Sep '96

10 Oct '96

10 Dec '96

10 Jan '97

10 Feb '97

10 Apr '97

10 Jun '97

10 Jul '97

10 Sep '97

10 Oct '97

10 Dec '97

10 Jan '98

10 Feb '98

10 Apr '98

10 Jun '98

$10 \mathrm{Jul}$ '98

10 Sep '98

10 Oct '98

10 Nov'98

10 Dec '98

10 Jan '99

10 Feb '99

10 Apr '99

10 Jun '99

10 Jul '99

10 Sep '99

10 Oct '99

10 Dec '99

10 Jan '00 


\begin{tabular}{|c|c|c|c|c|}
\hline 02 Feb '00 & 27 Jan '00 & 10 Jan '00 & 10 Jan '00 & 10 Feb '00 \\
\hline 21 Mar '00 & 15 Mar '00 & 10 Mar '00 & 10 Mar '00 & 10 Apr '00 \\
\hline 16 May '00 & 11 May '00 & 10 May '00 & 10 May '00 & 10 Jun '00 \\
\hline 28 Jun '00 & 21 Jun '00 & 10 Jun '00 & 10 Jun '00 & $10 \mathrm{Jul}$ '00 \\
\hline 22 Aug '00 & 16 Aug '00 & 10 Aug '00 & 10 Aug '00 & 10 Sep '00 \\
\hline 03 Oct '00 & 27 Sep '00 & 10 Sep '00 & 10 Sep '00 & 10 Oct '00 \\
\hline 15 Nov '00 & 08 Nov '00 & 10 Nov '00 & 10 Nov '00 & 10 Dec '00 \\
\hline 19 Dec '00 & 13 Dec '00 & 10 Dec '00 & 10 Dec '00 & 10 Jan '01 \\
\hline 03 Jan '01 & & 10 Dec '00 & 10 Dec '00 & 10 Jan '01 \\
\hline 31 Jan '01 & 25 Jan '01 & 10 Jan '01 & 10 Jan '01 & 10 Feb '01 $^{\prime}$ \\
\hline 20 Mar '01 & 14 Mar '01 & 10 Mar '01 & 10 Mar '01 & 10 Apr '01 \\
\hline 18 Apr '01 & & 10 Apr '01 & 10 Apr '01 & 10 May '01 \\
\hline 15 May '01 & 09 May '01 & 10 May '01 & 10 May '01 & 10 Jun '01 \\
\hline 27 Jun '01 & 20 Jun '01 & 10 Jun '01 & 10 Jun '01 & 10 Jul '01 \\
\hline 21 Aug '01 & 16 Aug '01 & 10 Aug '01 & 10 Aug '01 & 10 Sep '01 \\
\hline 02 Oct '01 & 27 Sep '01 & 10 Sep '01 & 10 Sep '01 & 10 Oct ' 0 \\
\hline 06 Nov '01 & 31 Oct '01 & 10 Oct '01 & 10 Oct '01 & 10 Nov '0 \\
\hline 11 Dec '01 & 05 Dec '01 & 10 Dec '01 & 10 Dec '01 & 10 Jan '02 \\
\hline 30 Jan '02 & 23 Jan '02 & 10 Jan '02 & 10 Jan '02 & 10 Feb '02 \\
\hline 19 Mar '02 & 13 Mar '02 & 10 Mar '02 & 10 Mar '02 & 10 Apr ' \\
\hline 07 May '02 & 01 May '02 & 10 Apr '02 & 10 Apr '02 & 10 May '( \\
\hline 26 Jun '02 & 20 Jun '02 & 10 Jun '02 & 10 Jun '02 & $10 \mathrm{Jul}$ '02 \\
\hline 13 Aug '02 & 07 Aug '02 & 10 Aug '02 & 10 Aug '02 & 10 Sep '0 \\
\hline 24 Sep '02 & 18 Sep '02 & 10 Sep '02 & 10 Sep '02 & 10 Oct '0 \\
\hline 06 Nov '02 & 30 Oct '02 & 10 Oct '02 & 10 Oct '02 & 10 Nov 'c \\
\hline 10 Dec '02 & 04 Dec '02 & 10 Nov '02 & 10 Nov '02 & 10 Dec '0 \\
\hline 29 Jan '03 & 22 Jan '03 & 10 Jan '03 & 10 Jan '03 & 10 Feb 'c \\
\hline 18 Mar '03 & 13 Mar '03 & 10 Mar '03 & 10 Mar '03 & 10 Apr 'C \\
\hline 06 May '03 & 30 Apr '03 & 10 Apr '03 & 10 Apr '03 & 10 May 'C \\
\hline 25 Jun '03 & 18 Jun '03 & 10 Jun '03 & 10 Jun '03 & $10 \mathrm{Jul}$ '03 \\
\hline 12 Aug '03 & 06 Aug '03 & 10 Aug '03 & 10 Aug '03 & 10 Sep '03 \\
\hline 16 Sep '03 & 10 Sep '03 & 10 Sep '03 & 10 Sep '03 & 10 Oct '0 \\
\hline 28 Oct '03 & 22 Oct '03 & 10 Oct '03 & 10 Oct '03 & 10 Nov '0 \\
\hline 09 Dec '03 & 03 Dec '03 & 10 Nov '03 & 10 Nov '03 & 10 Dec 'c \\
\hline 28 Jan '04 & 21 Jan '04 & 10 Jan '04 & 10 Jan '04 & 10 Feb '04 \\
\hline 16 Mar '04 & 11 Mar '04 & 10 Mar '04 & 10 Mar '04 & 10 Apr 'o \\
\hline 04 May '04 & 28 Apr '04 & 10 Apr '04 & 10 Apr '04 & 10 May '0 \\
\hline 30 Jun '04 & 23 Jun '04 & 10 Jun '04 & 10 Jun '04 & $10 \mathrm{Jul}$ '0 \\
\hline 10 Aug '04 & 05 Aug '04 & 10 Jul '04 & $10 \mathrm{Jul}$ '04 & 10 Aug 'C \\
\hline 21 Sep '04 & 15 Sep '04 & 10 Sep '04 & 10 Sep '04 & 10 Oct 'c \\
\hline 10 Nov '04 & 03 Nov '04 & 10 Oct '04 & 10 Oct '04 & 10 Nov 'c \\
\hline 14 Dec '04 & 08 Dec '04 & 10 Dec '04 & 10 Dec '04 & 10 Jan '0 \\
\hline 02 Feb '05 & 26 Jan '05 & 10 Jan '05 & 10 Jan '05 & 10 Feb '0 \\
\hline 22 Mar '05 & 16 Mar '05 & 10 Mar '05 & 10 Mar '05 & 10 Apr '0 \\
\hline 03 May '05 & 28 Apr '05 & 10 Apr '05 & 10 Apr '05 & 10 May 'C \\
\hline 30 Jun '05 & 22 Jun '05 & 10 Jun '05 & 10 Jun '05 & $10 \mathrm{Jul}$ '05 \\
\hline 09 Aug '05 & 04 Aug '05 & $10 \mathrm{Jul}$ '05 & $10 \mathrm{Jul}$ '05 & 10 Aug '0 \\
\hline 20 Sep '05 & 14 Sep '05 & 10 Sep '05 & 10 Sep '05 & 10 Oct 0 \\
\hline
\end{tabular}




\begin{tabular}{|c|c|c|c|c|}
\hline 01 Nov '05 & 26 Oct '05 & 10 Oct '05 & 10 Oct '05 & 10 Nov '05 \\
\hline 13 Dec '05 & 07 Dec '05 & 10 Dec '05 & 10 Dec '05 & 10 Jan '06 \\
\hline 31 Jan '06 & 25 Jan '06 & 10 Jan '06 & 10 Jan '06 & 10 Feb '06 \\
\hline 28 Mar '06 & 22 Mar '06 & 10 Mar '06 & 10 Mar '06 & 10 Apr '06 \\
\hline 10 May '06 & 03 May '06 & 10 Apr '06 & 10 Apr '06 & 10 May '06 \\
\hline 29 Jun '06 & 21 Jun '06 & 10 Jun '06 & 10 Jun '06 & $10 \mathrm{Jul}$ '06 \\
\hline 08 Aug '06 & 03 Aug '06 & $10 \mathrm{Jul}$ '06 & 10 Jul '06 & 10 Aug '06 \\
\hline 20 Sep '06 & 13 Sep '06 & 10 Sep ’06 & 10 Sep '06 & 10 Oct '06 \\
\hline 25 Oct '06 & 18 Oct '06 & 10 Oct '06 & 10 Oct '06 & 10 Nov '06 \\
\hline 12 Dec '06 & 06 Dec '06 & 10 Dec '06 & 10 Dec '06 & 10 Jan '07 \\
\hline 31 Jan '07 & 24 Jan '07 & 10 Jan '07 & 10 Jan '07 & 10 Feb '07 \\
\hline 21 Mar '07 & 14 Mar '07 & 10 Mar '07 & 10 Mar '07 & 10 Apr '07 \\
\hline 09 May '07 & 02 May '07 & 10 Apr '07 & 10 Apr ’07 & 10 May '07 \\
\hline 28 Jun '07 & 20 Jun '07 & 10 Jun '07 & 10 Jun '07 & $10 \mathrm{Jul}$ '07 \\
\hline 07 Aug '07 & 02 Aug '07 & $10 \mathrm{Jul}$ '07 & $10 \mathrm{Jul}$ '07 & 10 Aug '07 \\
\hline 17 Aug '07 & & 10 Aug '07 & 10 Aug '07 & 10 Sep '07 \\
\hline 18 Sep '07 & 12 Sep '07 & 10 Sep '07 & 10 Sep '07 & 10 Oct '07 \\
\hline 31 Oct '07 & 24 Oct '07 & 10 Oct '07 & 10 Oct ' 07 & 10 Nov '07 \\
\hline 11 Dec '07 & 05 Dec ’07 & 10 Dec '07 & 10 Dec '07 & 10 Jan '08 \\
\hline 22 Jan '08 & & 10 Jan '08 & 10 Jan '08 & 10 Feb '08 \\
\hline 30 Jan '08 & 23 Jan '08 & 10 Jan '08 & 10 Jan '08 & 10 Feb '08 \\
\hline 18 Mar '08 & 13 Mar '08 & 10 Mar '08 & 10 Mar '08 & 10 Apr '08 \\
\hline 30 Apr '08 & 23 Apr '08 & 10 Apr '08 & 10 Apr '08 & 10 May '08 \\
\hline 25 Jun '08 & 18 Jun '08 & 10 Jun '08 & 10 Jun '08 & 10 Jul '08 \\
\hline 05 Aug '08 & $30 \mathrm{Jul}$ '08 & $10 \mathrm{Jul}$ '08 & $10 \mathrm{Jul}$ '08 & 10 Aug '08 \\
\hline 16 Sep '08 & 10 Sep '08 & 10 Sep ’08 & 10 Sep '08 & 10 Oct '08 \\
\hline 08 Oct '08 & & 10 Sep ’08 & 10 Sep '08 & 10 Oct '08 \\
\hline 29 Oct '08 & 22 Oct '08 & 10 Oct '08 & 10 Oct '08 & 10 Nov '08 \\
\hline 25 Nov '08 & & 10 Nov '08 & 10 Nov '08 & 10 Dec '08 \\
\hline 16 Dec '08 & 10 Dec '08 & 10 Dec '08 & 10 Dec '08 & 10 Jan '09 \\
\hline 28 Jan '09 & 22 Jan '09 & 10 Jan '09 & 10 Jan '09 & 10 Feb '09 \\
\hline 18 Mar '09 & 12 Mar '09 & 10 Mar '09 & 10 Mar '09 & 10 Apr '09 \\
\hline 29 Apr '09 & 22 Apr '09 & 10 Apr '09 & 10 Apr ’09 & 10 May '09 \\
\hline 24 Jun '09 & 17 Jun '09 & 10 Jun '09 & 10 Jun '09 & $10 \mathrm{Jul}$ '09 \\
\hline 12 Aug '09 & 06 Aug '09 & 10 Aug '09 & 10 Aug '09 & 10 Sep '09 \\
\hline 23 Sep '09 & 16 Sep '09 & 10 Sep '09 & 10 Sep '09 & 10 Oct '09 \\
\hline 04 Nov '09 & 29 Oct '09 & 10 Oct '09 & 10 Oct '09 & 10 Nov '09 \\
\hline 16 Dec '09 & 09 Dec '09 & 10 Dec '09 & 10 Dec '09 & 10 Jan '10 \\
\hline 27 Jan '10 & 20 Jan '10 & 10 Jan '10 & 10 Jan '10 & 10 Feb '10 \\
\hline 16 Mar '10 & 10 Mar '10 & 10 Mar '10 & 10 Mar '10 & 10 Apr '10 \\
\hline 28 Apr '10 & $21 \mathrm{Apr}$ '10 & 10 Apr '10 & 10 Apr '10 & 10 May '10 \\
\hline 23 Jun '10 & 16 Jun '10 & 10 Jun '10 & 10 Jun '10 & 10 Jul '10 \\
\hline 10 Aug '10 & 04 Aug '10 & $10 \mathrm{Jul}$ '10 & $10 \mathrm{Jul}$ '10 & 10 Aug '10 \\
\hline 21 Sep '10 & 15 Sep '10 & 10 Sep '10 & 10 Sep '10 & 10 Oct '10 \\
\hline 03 Nov '10 & 27 Oct '10 & 10 Oct '10 & 10 Oct '10 & 10 Nov '10 \\
\hline 14 Dec '10 & 08 Dec '10 & 10 Dec '10 & 10 Dec '10 & 10 Jan '11 \\
\hline 26 Jan '11 & 19 Jan '11 & 10 Jan '11 & 10 Jan '11 & 10 Feb '11 \\
\hline 15 Mar '11 & 09 Mar '11 & 10 Mar '11 & 10 Mar '11 & 10 Apr '11 \\
\hline
\end{tabular}




\begin{tabular}{lllll} 
27 Apr '11 & 20 Apr '11 & 10 Apr '11 & 10 Apr '11 & 10 May '11 \\
22 Jun '11 & 15 Jun '11 & 10 Jun '11 & 10 Jun '11 & 10 Jul '11 \\
09 Aug '11 & 03 Aug '11 & 10 Jul '11 & 10 Jul '11 & 10 Aug '11 \\
21 Sep '11 & 14 Sep '11 & 10 Sep '11 & 10 Sep '11 & 10 Oct '11 \\
02 Nov '11 & 26 Oct '11 & 10 Oct '11 & 10 Oct '11 & 10 Nov '11 \\
13 Dec '11 & 07 Dec '11 & 10 Dec '11 & 10 Dec '11 & 10 Jan '12 \\
25 Jan '12 & 18 Jan '12 & 10 Jan '12 & 10 Jan '12 & 10 Feb '12 \\
13 Mar '12 & 07 Mar '12 & 10 Mar '12 & 10 Mar '12 & 10 Apr '12 \\
25 Apr '12 & 18 Apr '12 & 10 Apr '12 & 10 Apr '12 & 10 May '12 \\
20 Jun '12 & 13 Jun '12 & 10 Jun '12 & 10 Jun '12 & 10 Jul '12 \\
01 Aug '12 & 25 Jul '12 & 10 Jul '12 & 10 Jul '12 & 10 Aug '12 \\
13 Sep '12 & 05 Sep '12 & 10 Sep '12 & 10 Sep '12 & 10 Oct '12 \\
24 Oct '12 & 17 Oct '12 & 10 Oct '12 & 10 Oct '12 & 10 Nov '12 \\
12 Dec '12 & 05 Dec '12 & 10 Dec '12 & 10 Dec '12 & 10 Jan '13 \\
30 Jan '13 & 23 Jan '13 & 10 Jan '13 & 10 Jan '13 & 10 Feb '13 \\
20 Mar '13 & 13 Mar '13 & 10 Mar '13 & 10 Mar '13 & 10 Apr '13 \\
01 May '13 & 24 Apr '13 & 10 Apr '13 & 10 Apr '13 & 10 May '13 \\
19 Jun '13 & 12 Jun '13 & 10 Jun '13 & 10 Jun '13 & $10 \mathrm{Jul} \mathrm{'13}$ \\
31 Jul '13 & 24 Jul '13 & 10 Jul '13 & 10 Jul '13 & 10 Aug '13 \\
18 Sep '13 & 11 Sep '13 & 10 Sep '13 & 10 Sep '13 & 10 Oct '13 \\
30 Oct '13 & 23 Oct '13 & 10 Oct '13 & 10 Oct '13 & 10 Nov '13 \\
18 Dec '13 & 12 Dec '13 & 10 Dec '13 & 10 Dec '13 & 10 Jan '14 \\
\hline
\end{tabular}

